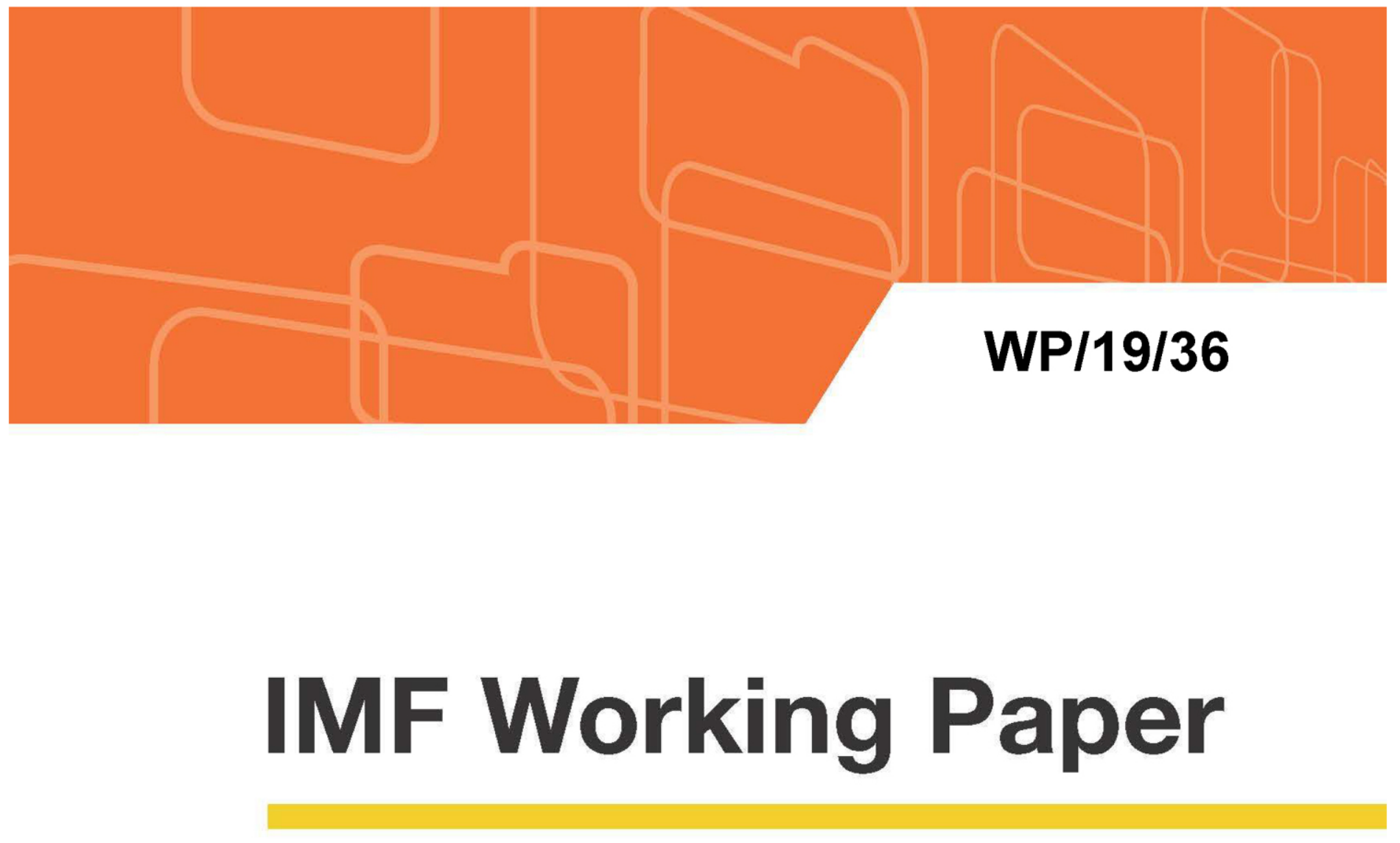

\title{
Growth at Risk: Concept and Application in IMF Country Surveillance
}

\author{
Ananthakrishnan Prasad, Selim Elekdag, Phakawa Jeasakul, Romain Lafarguette, \\ Adrian Alter, Alan Xiaochen Feng, and Changchun Wang
}

IMF Working Papers describe research in progress by the author(s) and are published to elicit comments and to encourage debate. The views expressed in IMF Working Papers are those of the author(s) and do not necessarily represent the views of the IMF, its Executive Board, or IMF management. 


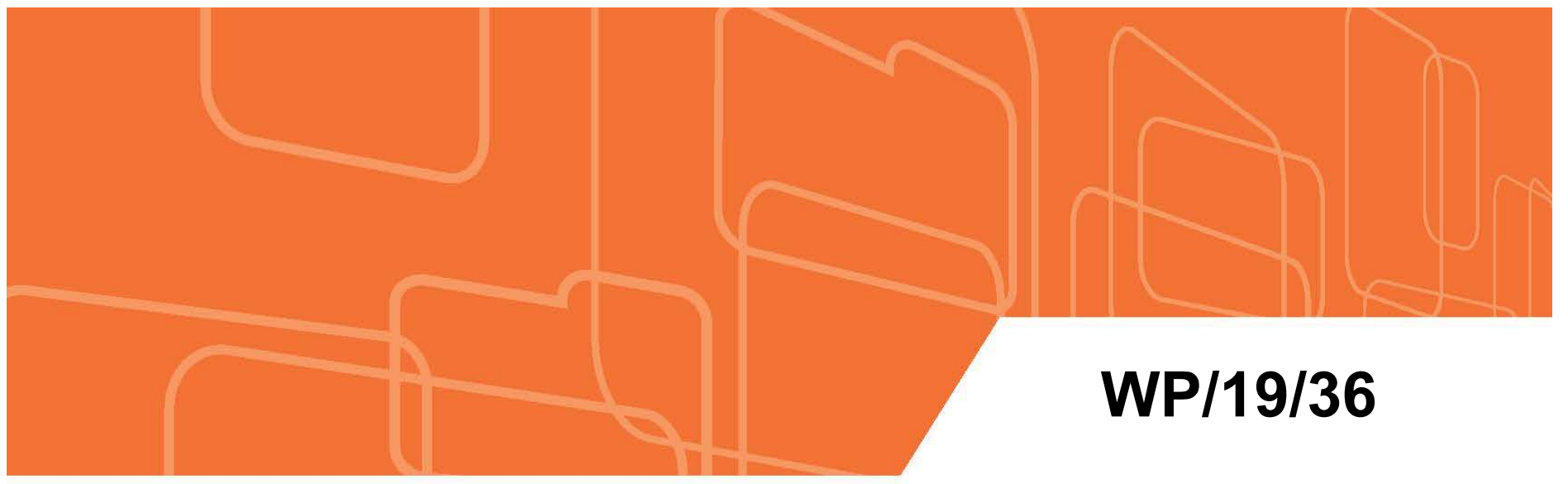

\section{IMF Working Paper}

\section{Growth at Risk: Concept and Application in IMF Country Surveillance} Ananthakrishnan Prasad, Selim Elekdag, Phakawa Jeasakul, Romain Lafarguette,
Adrian Alter, Alan Xiaochen Feng, and Changchun Wang

IMF Working Papers describe research in progress by the author(s) and are published to elicit comments and to encourage debate. The views expressed in IMF Working Papers are those of the author(s) and do not necessarily represent the views of the IMF, its Executive Board, or IMF management.

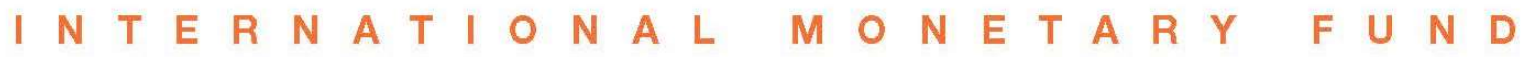




\title{
IMF Working Paper
}

Monetary and Capital Markets Department

\section{Growth at Risk: Concept and Application in IMF Country Surveillance}

Prepared by Ananthakrishnan Prasad, Selim Elekdag, Phakawa Jeasakul, Romain Lafarguette, Adrian Alter, Alan Xiaochen Feng, and Changchun Wang ${ }^{1}$

February 2019

\section{IMF Working Papers describe research in progress by the author(s) and are published to elicit comments and to encourage debate. The views expressed in IMF Working Papers are those of the author(s) and do not necessarily represent the views of the IMF, its Executive Board, or IMF management.}

\begin{abstract}
The growth-at-risk $(\mathrm{GaR})$ framework links current macrofinancial conditions to the distribution of future growth. Its main strength is its ability to assess the entire distribution of future GDP growth (in contrast to point forecasts), quantify macrofinancial risks in terms of growth, and monitor the evolution of risks to economic activity over time. By using GaR analysis, policymakers can quantify the likelihood of risk scenarios, which would serve as a basis for preemptive action. This paper offers practical guidance on how to conduct GaR analysis and draws lessons from country case studies. It also discusses an Excel-based GaR tool developed to support the IMF's bilateral surveillance efforts.

JEL Classification Numbers: E1, E17, F44, G1

Keywords: downside risk, macrofinancial linkages, financial stability

\footnotetext{
${ }^{1}$ The Growth-at-Risk Excel/Python-based tool was developed by Romain Lafarguette and Changchun Wang, in collaboration with Aquiles Farias, Kei Moriya, and Heesun Kiem (all of the IMF's Information Technology Department); the tool and the codes are available on Github (https://github.com/IMFGAR/GaR) along with proper documentation, user-guide and technical appendix. We thank Tobias Adrian, James Morsink, Sheheryar Malik, Raphael Espinoza, and participants in the IMF AFR, APD, EUR, FAD, MCD, MCM, SPR, and WHD department seminars for their insightful suggestions. We also thank Katya Botsu and Elizabeth Mahoney for their excellent editorial and research assistance, respectively.
} 
Author email addresses: APrasad@imf.org, SElekdag@imf.org, PJeasakul@imf.org, RLafarguette@,imf.org, AAlter@imf.org, XFeng@imf.org, CWang2@,imf.org

\section{Contents}

I. INTRODUCTION

II. GROWTH-AT-RISK: WHAT IS IT ABOUT?

A. Conceptual Underpinnings

B. Empirical Approach

III. GROWTH-AT-RISK ANALYSIS IN IMF BILLATERAL MACROFINANCIAL SURVEILLANCE

IV. PRACTICAL GUIDANCE ON HOW TO CONDUCT GROWTH-AT-RISK ANALYSIS

A. Step 1: Selecting Macrofinancial Variables and Constructing Partitions

B. Step 2: Quantile Regression Estimation

C. Step 3: Deriving the Conditional Future Growth Distributions

D. Assessing the Plausibility of Baseline and Alternative Scenarios

E. Exploring the Effects of Risk Materialization

V. CONCLUSION $\underline{32}$

BOXES

1. Case Study: 2018 Peru FSAP 11

2. Case Study: 2018 Article IV Consultation with Portugal 13

3. Case Study: 2018 Article IV Consultation with Singapore 15

4. Constructing a Financial Conditions Partition 19

5. Example of Macrofinancial Vulnerabilities Partition 22

6. Example of an $\underline{24}$

7. Example of Quantile Regression Estimation ___ 26

8. Examples of the GaR Analysis Outputs ___ 29

9. Example of Scenario Analysis ___

\section{TABLES}

1. List of Potential Variables Representing Financial Conditions $\underline{18}$

2. List of Potential Variables Representing Macrofinancial Vulnerabilities $\underline{21}$ 


\section{INTRODUCTION}

Changes in the state of the financial system and the evolution of macrofinancial vulnerabilities can provide powerful signals about evolving risks to future economic activity. Macrofinancial vulnerabilities often increase in times of buoyant economic conditions when funding is widely available and risk measures are subdued. Tightening of these financial conditions, particularly when macrofinancial vulnerabilities are elevated, pose significant downside risks to economic activity. Thus, tracking the evolution of financial conditions and macrofinancial vulnerabilities can provide valuable information for policymakers regarding risks to future growth and, hence form a basis for targeted preemptive action.

The growth-at-risk $(\mathrm{GaR})$ framework links macrofinancial conditions to the probability distribution of future real GDP growth, and offers a number of appealing features that enhance macrofinancial surveillance. First, it draws attention to the entire growth distribution - encompassing both downside and upside risks — and so goes beyond more traditional point forecasts. Second, it provides a framework for analyzing the key drivers of future GDP growth, including their relative importance, which vary across the growth distribution and the forecasting horizon. Third, it helps quantify the impact of systemic risk on future GDP growth and therefore holds promise for guiding macroprudential policy. In sum, GaR analysis can appreciably expand the macrofinancial surveillance toolkits of policymakers.

Policymaking stands to benefit from information about the entire growth distribution provided by $\mathrm{GaR}$ analysis. Policymakers typically conduct policy based on central-scenario macroeconomic projections. For example, an inflation-targeting central bank adjusts its policy interest rate to ensure that the inflation target is met. At the same time, they also communicate risks surrounding their point forecasts (central scenarios), for example by using fan charts in the presentation of inflation projections. With an entire distribution at their disposal, they may opt for policy stances that minimize risks rather than optimize outcomes under the central scenario. This is why deriving the distribution of future GDP growth based on macrofinancial conditions could be particularly useful for policy makers with a mandate for financial stability and macroprudential policy. Using GaR analysis, policymakers can 
quantify the likelihood of risk scenarios, verify whether central scenarios are too optimistic or pessimistic, and more readily communicate the nature of these risks to a wider audience.

The relative importance of the key drivers of future GDP growth across the growth distribution and the forecasting horizon could be insightful for policymakers. For instance, in the near term, favorable financial conditions, possibly driven by compressed risk premiums, subdued asset price volatility, and rapid credit growth, help support growth. But over the medium term, loose financial conditions induce a buildup of macrofinancial imbalances that could undermine growth down the road. Similarly, the relative importance of these key driving factors could vary across the future growth distribution. Understanding the key driving factors at the left tail of the distribution would help prepare policymakers for dealing with severe downside risks.

Although GaR analysis is not structural, and thus cannot ascertain causal links, it can help quantify the macroeconomic impact of systemic risk, potentially supporting macroprudential policy implementation. The GaR framework makes it possible to evaluate the severity of systemic risk (for example, resulting from improper risk pricing and mounting macrofinancial vulnerabilities) and its growth implications including through scenario analysis. However, although $\mathrm{GaR}$ is a flexible and parsimonious approach, it is also a reduced-form framework most appropriate for comparative statics analysis. GaR also holds promise as an approach to quantify the intertemporal tradeoff associated with a tighter macroprudential stance: while such a policy tightening could induce a mild short-term slowdown, it could lower medium-term risks to growth owing to reduced macrofinancial vulnerabilities.

More recently, the GaR approach has been incorporated into the International Monetary Fund's macrofinancial surveillance toolkit. In the context of multilateral surveillance, the Global Financial Stability Report (GFSR) has explored tail risk to global economic growth based on prevailing global financial conditions (see IMF 2017a, IMF 2017b, IMF 2018a, and IMF 2018b). In the context of bilateral surveillance, a number of Article IV consultations have started using $\mathrm{GaR}$ analysis to enhance macrofinancial analysis and policy discussions. ${ }^{2}$

This paper provides an overview of how GaR analysis can be used in the Fund's surveillance work. Section II discusses what GaR is about, including its conceptual underpinnings and its use in empirical research. Section III provides an overview on how GaR analysis has been applied in the context of Fund bilateral surveillance, and Section IV offers some practical guidance on how to conduct GaR analysis. Section $\mathrm{V}$ concludes.

\footnotetext{
2 "Article IV consultations" (as required by Article IV of the IMF's Articles of Agreement) are part of an ongoing country surveillance process that culminates in regular (usually annual) comprehensive consultations with individual member countries to assess and discuss the country's economic and financial policies with government and central bank officials, for further details, see https://www.imf.org/external/about/econsurv.htm
} 


\section{Growth-AT-Risk: What IS IT AbOUt?}

This section discusses the conceptual underpinnings and an overview of the empirical approach of GaR.

\section{A. Conceptual Underpinnings}

Theory and recent experience support the view that macrofinancial vulnerabilities increase risks to growth. When investment opportunities seem abundant and financing is easily and cheaply available, macrofinancial vulnerabilities tend to increase. Once such vulnerabilities are sufficiently high, they can amplify and prolong the impact of shocks on economic activity. Economic growth responds nonlinearly to adverse shocks in the presence of macrofinancial vulnerabilities, potentially resulting in significant financial stress and severely negative macroeconomic outcomes. Empirical evidence shows that recessions accompanied by financial crises are typically much more severe and protracted than ordinary recessions (IMF, 2008; Cardarelli, Elekdag, and Lall, 2011; Claessens, Kose, and Terrones, 2012). Under such circumstances, assessments of both the baseline growth outlook and the risks to such an outlook are informed not only by the span and severity of relevant risk factors that are the source of shocks, but also by an understanding of the interplay of factors that increase macrofinancial vulnerabilities.

Several factors cause macrofinancial vulnerabilities to grow in a buoyant macroeconomic environment. Ease of borrowing and high asset prices reduce incentives to manage liquidity and solvency risks. Perceptions of high investment returns and of improved quality of collateral incentivize firms and households to increase leverage without considering the resulting negative externalities from their collective borrowing decisions (Bianchi 2011; Korinek and Simsek 2016). Booming asset prices and low volatility also boost the solvency position, lending capacity, and risk appetite of financial intermediaries (Brunnermeier and Pedersen 2009; Adrian, Moench, and Shin 2010; Adrian and Shin 2014). These factors lead to excessive risk-taking activities in the financial system, which entail an accumulation of macrofinancial vulnerabilities in the form of increased leverage, mismatches of maturity and financial positions, growing indebtedness, reduced debt servicing capacity, and other balance sheet weaknesses.

Macrofinancial vulnerabilities can amplify and prolong the impact of adverse shocks to economic activity. The need to deleverage and correct balance sheet mismatches can clog financial intermediation and undermine economic growth for a long time. With substantially elevated vulnerabilities, even small negative shocks can cause significant adjustments. Some borrowers may be forced into default, with ensuing pressure on lenders' profits and balance sheets. Such direct effects - together with rising volatility, falling asset prices, and widening risk spreads - constrain lenders' capacity to bear risk given the need for additional capital buffers, prompting them to deleverage and liquidate assets (He and Krishnamurthy 2013; Brunnermeier and Sannikov 2014). Furthermore, risk-bearing capacity can also be affected 
by concerns about access to funds (Gertler, Kiyotaki, and Prestipino 2017). At the same time, highly leveraged firms and households may also face financial constraints (Kiyotaki and Moore 1997). In all, the impact of adverse shocks on economic activity can last for a long time due to impaired financial intermediation and debt overhang.

A large body of empirical work has examined how the information content of financial conditions can improve growth point forecasts. ${ }^{3}$ For example, asset prices are useful predictors of future output growth in some countries and in some periods. Short-term yields on risk-free securities and term spreads capture the stance of monetary policy and contain useful information on future economic activity (Laurent 1988; Estrella and Hardouvelis 1991; Bernanke and Blinder 1992; Estrella and Mishkin 1998; Ang, Piazzesi, and Wei 2006). Corporate bond spreads signal changes in the default-adjusted marginal return on business fixed investment (Philippon 2009), and in profitability and credit worthiness of financial and nonfinancial entities (Gilchrist and Zakrajšek 2012). There is some evidence that elevated volatility of stock returns can be a useful predictor of output contractions in the near term (Campbell and others 2001).

The GaR framework goes beyond traditional point forecasts by using measures of financial conditions and macrofinancial vulnerabilities to forecast the entire distribution of GDP growth. ${ }^{4}$ Besides asset prices, credit aggregates may provide information on the risks to growth at different time horizons. For example, a combination of low leverage and buoyant asset prices are likely to correspond, over the short term, to higher expected growth (an optimistic baseline outlook) and a lower likelihood of adverse outcomes (a sanguine risk outlook). On the other hand, theory suggests that this might be an ideal environment for macrofinancial vulnerabilities to build up over the medium term, ultimately increasing the likelihood of subdued growth prospects. ${ }^{5}$ Empirically, asset prices tend to be more informative about downside risks to growth in the short term for many countries, while credit aggregates, such as corporate and household leverage, appear to more robustly signal downside risks to growth in the medium term (IMF 2017b). ${ }^{6}$

\footnotetext{
${ }^{3}$ Stock and Watson (2003) and Hatzius and others (2010) provided comprehensive surveys of the literature.

${ }^{4}$ Growth at risk (GaR) corresponds to the probability of future real GDP growth falling below a prespecified threshold. More precisely, and in line with Adrian and others (2018), GaR is defined as:
}

$$
\text { Probability }\left(\text { growth }_{c, h} \leq \operatorname{GaR}_{c, h}\left(\alpha \mid \Omega_{t}\right)\right)=\alpha
$$

where $\operatorname{GaR}_{c, h}\left(\alpha \mid \Omega_{t}\right)$ is growth at risk for country $c$ in $h$ quarters in the future at an $\alpha$ probability with $\Omega_{t}$ denoting the information set available at time $t$.

${ }^{5}$ IMF (2017c) also found that a rise in household debt corresponded to a short-term boost to growth while elevating medium-term risks to macroeconomic and financial stability.

${ }^{6}$ Although financial conditions affect the expected growth distribution in many countries, macroeconomic models and forecasting practices predominantly focus on expected mean growth, and usually do not model the

(continued...) 
GaR analysis centers on empirically forecasting the probability distribution of future GDP growth in a way that allows for nonlinearity and state dependence. Building on the conditional density forecasting literature, recent research has used financial conditions to forecast the probability distribution of future GDP growth at various horizons through quantile projections. $^{7}$ The advantage of this approach is that it flexibly captures the rich nonlinear interaction between shocks, financial conditions, and economic outcomes predicted by theory. ${ }^{8}$ These density forecasts can subsequently be exploited to construct a measure of risks to economic growth associated with prevailing macro financial conditions. For instance, GaR analysis can quantify both upside and downside risks to the growth outlook in addition to standard point forecasts. ${ }^{9} \mathrm{GaR}$ also provides a parsimonious, reduced-form framework to analyze macrofinancial linkages, including by estimating the relative importance of the key drivers of future growth (across growth quantiles and forecasting horizons).

\section{B. Empirical Approach}

The GaR framework provides a tractable estimation of the severity and the likeliood of a sharp economic slowdown. In the spirit of the Value-at-Risk concept in finance, GaR is designed to gauge the likelihood of severely adverse macroeconomic outcomes. The April 2017 edition of the GFSR introduced the GaR concept (IMF 2017a), and the October 2017 edition provided the analytical underpinnings (IMF 2017b). Both reports analzyed how prevailing global financial conditions may affect tail risks to global economic activity. Building on the literature that highlights the importance of financial conditions in driving economic activity, the analysis first established the relationship between future GDP growth and macrofinancial conditions using the quantile regression approach. Then, the analysis

higher moments of the distribution. This focus on conditional growth for estimations can be too narrow when volatility and skewness increase as growth weakens and may lead to a systematic underestimation of downside tail risks.

7 The conditional density forecasting literature is surveyed by Tay and Wallis (2000), Corradi and Swanson (2006), and Komunjer (2013). Note also that De Nicolo and Lucchetta (2017) establish a direct empirical link between financial conditions and risks to future economic growth.

8 Although the specification of each quantile regression is linear, the relationship between the macrofinancial variables and future growth (distributions) is based on a collection of quantile regressions, each capturing different slopes at different points on the future growth distribution. Therefore, the relationship is nonlinear in the sense that a shock to a macrofinancial variables will affect future growth differentially depending on the point of the distribution of growth (in line with the underlying quantile regression).

${ }^{9}$ Furthermore, the approach offers the ability to define a level of risk tolerance in terms of GDP growth, which is more general than measuring the downside risks to growth in terms of the probability of a financial crisis defined under certain criteria. For instance, this approach yields answers to questions such as the probability of negative GDP growth one-year ahead given the current macroeconomic and financial environment.

(continued...) 
derived the growth distribution by fitting a parametric distribution using the estimated growth quantiles - the technique advocated by Adrian, Boyarchenko, and Giannone (forthcoming). ${ }^{10}$

The distribution of future GDP growth is estimated based on information contained in macrofinancial variables. Hence, the macrofinancial variables selected for explaining their relationship with future growth is critical. To assess financial stability risks, IMF (2017a, 2017b) primarily focused on financial conditions. A financial condition index (FCI) was constructed comprising three subcomponents: the domestic price of risk (which is embedded in credit spreads, term spreads, short- and long-term interest rates, asset price returns, and volatility metrics), leverage (credit growth and the change in the credit-to-GDP ratio), and external conditions (such as commodity prices and a measure of global risk sentiment).

Building on these studies, this paper seeks to generalize the variable classification used to forecast future GDP growth. Namely, it suggests three "partitions" (that is, groupings) of related macrofinancial variables: ${ }^{11}$

- $\quad$ Financial conditions: This partition aims at capturing the price of risk embedded in asset prices, the ease of obtaining financing, the cost of funding, and the degree of financial stress. This partition is predominantly constructed using price-based financial market indicators and is akin to many FCIs used in the literature.

- $\quad$ Macrofinancial vulnerabilities: Going beyond leverage metrics, this partition seeks to reflect macrofinancial imbalances and sectoral balance sheet weaknesses. Growing macrofinancial vulnerabilities, such as deterioration in corporate and household balance sheets, construction booms fueled by house price bubbles, and increased dependence on foreign-currency funding, contribute to a buildup of systemic risk. Accordingly, measures of indebtedness, debt-servicing, and maturity and foreignexchange mismatches are prime candidates that could be included in this partition.

- $\quad$ Other factors: This partition recognizes that other determinants are likely to influence future growth, including external demand and, for instance, commodity prices. Such other factors could reflect risks summarized in country-specific Risk Assessment Matrices (RAMs) which are not captured by the financial conditions or macrofinancial vulnerabilities partitions. Accordingly, GaR-based scenario analysis can shed light on the impact of these risk factors on future growth prospects, thereby enriching the discussion of the RAM in the context of Fund surveillance.

\footnotetext{
${ }^{10}$ See also Adrian, Boyarchenko, and Giannone (2016).

${ }^{11}$ These partitions could be interrelated and mutually reinforcing. Although interaction could be considered, for ease of exposition, this paper will focus on examples using three partitions.
} 


\section{GroWTH-AT-RISK ANALYSIS IN IMF Billateral MACROFINANCIAL SURVEILLANCE}

This section presents an overview on how GaR has been applied in the context of Fund's bilateral macrofinancial surveillance.

The Fund began using the GaR framework in its macrofinancial surveillance in 2017. Beginning in April 2017, the GFSR has regularly discussed tail risks to the global economic outlook based on prevailing global financial conditions. The 2018 Peru Financial Sector Assessment Program (FSAP) pioneered the use of GaR analysis in the bilateral surveillance context. More recently, a number of Article IV consultations, including Canada, Panama, Portugal, and Singapore have included the GaR framework to assess risks to the economic outlook.

Although the focus of the GaR application differs, there are common themes across the bilateral surveillance reports. This section considers three published reports, namely the 2018 Peru FSAP and the 2018 Portugal and Singapore Article IV consultations. The main aspects of how GaR informed these bilateral surveillance reports are presented in Box 1, Box 2, and Box 3, respectively, and can be summarized as follows:

- In all three applications, GaR was used to identify the main risk factors to future growth based on a comprehensive set of macrofinancial variables grouped along the following broadly-defined paritions: (1) financial conditions - usually the domestic price of risk; (2) macrofinancial vulnerabilities - typically emphasizing leverage metrics; and (3) other factors - giving prominence to external conditions. ${ }^{12}$ Regarding the latter, China's growth (for example, in the Peru and Singapore cases) and commodity price fluctuations (in the Peru case) were identified as factors that disproportionately influence downside risks to future growth relative to the baseline outlook.

- The relative importance of selected macrofinancial variables was identified for the entire future growth distribution across multiple forecasting horizons. In the case of Peru, the contribution of external factors to tail risks were estimated to be twice as high as those associated with the price of risk and leverage. In the case of Portugal, the price of risk appears to provide the most powerful short-term signal, whereas credit aggregates are the most significant predictor of future growth over the medium term.

- $\mathrm{GaR}$ was used to assess the likelihood of an economic contraction or the plausibility of an adverse scenario. In the case of Singapore, the estimated probability of an

\footnotetext{
${ }^{12}$ As will be discussed in the next section, it is useful to categorize macrofinancial variables into several broad groups or "partitions" which can be constructed using several approaches.
} 
output contraction over time serves as an additional early warning indicator to help inform policy. In the case of Peru, the likelihood of the adverse scenario (which involved a severe recession) was assessed to guide stress testing scenario design.

\section{Box 1. Case Study: 2018 Peru FSAP}

GaR was first introduced in the context of bilateral surveillance during the 2018 Peru FSAP. The GaR framework was initially used to determine and prioritize groups of macrofinancial variables based on their impact on future GDP growth. Once the link between current macrofinancial conditions and future GDP growth was established, the GaR framework was used to derive the conditional distribution of future GDP growth and to analyze how the economy may be adversely impacted under certain shocks, including in the context of appraising stress testing scenarios for the banking system.

Peru's GaR estimation incorporated almost 30 macroeconomic and financial variables to model the conditional distribution of future GDP growth distribution at different horizons. Macroeconomic and financial variables were partitioned into three distinct categories, with each of them serving to capture a different dimension of the macrofinancial risks to future growth. The three partitions are (1) the domestic "price of risk," which mostly comprises spreads and volatility variables; (2) "leverage," which includes credit growth, the credit-to-GDP ratio, and bond market capitalization, and (3) "external conditions," which in the case of Peru captures China's growth and, for example, commodity prices. Another advantage of the partitioning approach is that it extracts common information about co-movements in financial markets, while ignoring idiosyncratic noise, which tends to be significant in the case of Peru where some markets are relatively illiquid (see IMF 2018c for details).

The GaR framework identified external conditions, leverage, and the price of risk in Peru as major factors that influence the tail risks to future GDP growth. While all three risk factors were found to have a statistically significant impact on future GDP growth, external conditions, which are mostly driven by China's growth and by foreign exchange developments in Peru, were nearly twice as likely to lead to tail outcomes for GDP growth (figure, top panels).

$\mathrm{GaR}$ was also used to inform stress testing scenario design. The stress tests conducted in collaboration with the banking supervisory authority (Superintendencia de Banca, Seguros y AFP) used baseline and adverse scenarios spanning three-year horizons. Although growth picks up in the baseline scenario, it slows down significantly for two consecutive years under the adverse scenario. The latter envisions annual real GDP growth shocks (relative to the baseline) of -3.6 percent, -5.1 percent, and -0.9 percent, respectively over the three-year scenario (figure, bottom left panel). The likelihood of Peru's real GDP growth path characterizing the adverse scenario was estimated via the GaR model. The likelihood of the adverse GDP growth of -1.2 percent (corresponding to a 5.1 percent deviation from the baseline) in the second year is estimated to be 4.2 percent, suggesting that the scenario is harsh, yet plausible (figure, bottom right panel). 


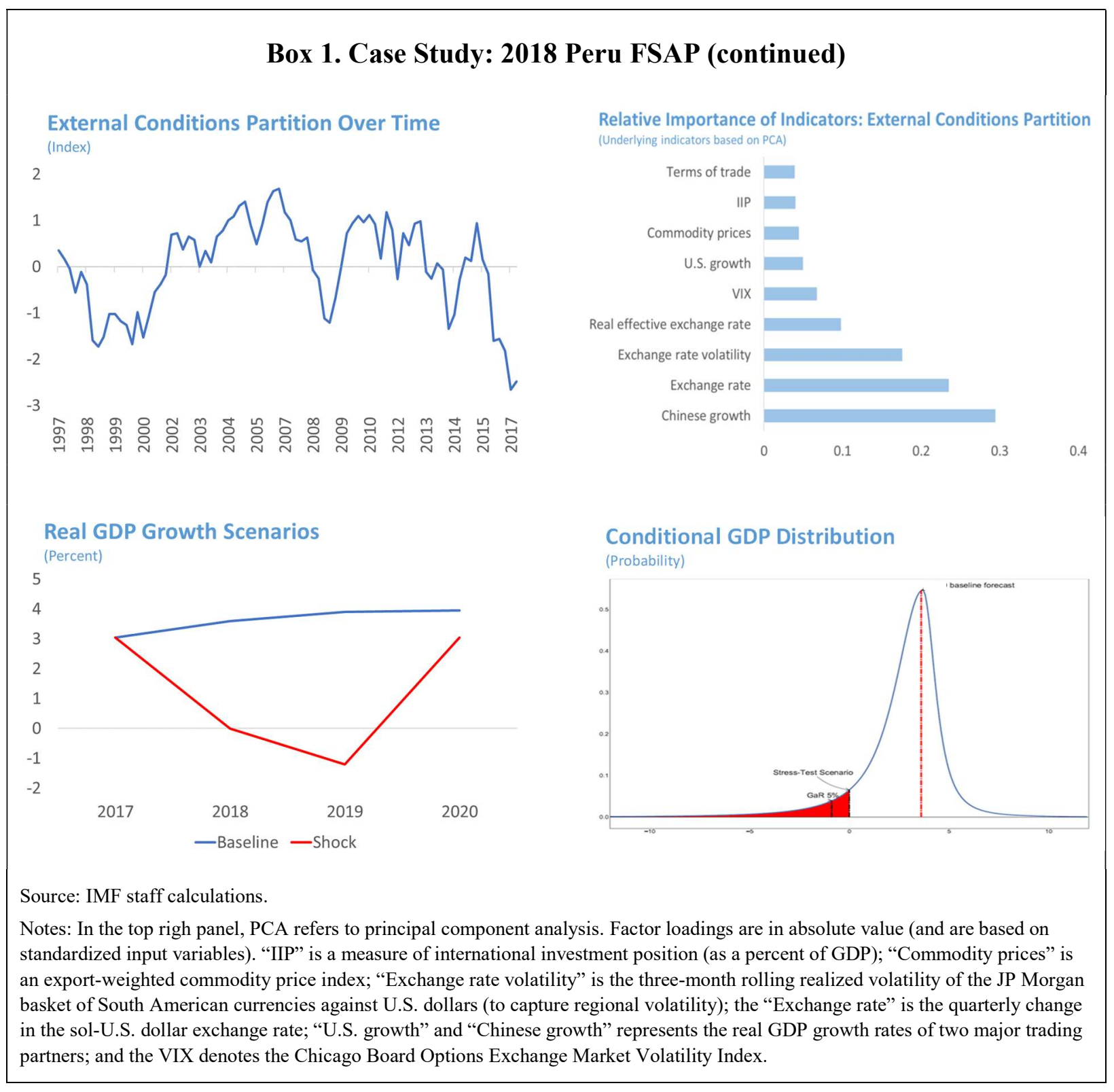

CInternational Monetary Fund. Not for Redistribution 


\section{Box 2. Case Study: 2018 Article IV Consultation with Portugal}

The GaR framework was used in the context of the 2018 Portugal Article IV consultation. After three years of lackluster economic recovery, real GDP growth in Portugal gained strength in 2017. The baseline scenario assumes that economic prospects will remain favorable over the medium term. However, the recovery is taking place in an environment of low interest rates and financial market volatility, as well as compressed risk premia, which may incentivize borrowers and lenders to take excessive risks, aggravating the still-elevated levels of leverage, and thereby posing risks to financial stability.

Measures of the price of risk, credit aggregates, and external conditions appear to predict episodes of severe economic weakness well in Portugal. A large set of macrofinancial variables are partitioned into three groups based on their economic similarity: (1) the price of risk (including various interest rates, spreads, and asset price returns), (2) credit aggregates (including both ratios and growth rates of credit), and (3) external conditions (such as the VIX, oil prices, and euro area growth, excluding Portugal).

The results from the quantile regressions suggest a nonlinear relationship between macrofinancial conditions and future GDP growth. The analysis highlights the importance of the price of risk, leverage, and credit growth as leading indicators of downside risks to growth. In particular, the price of risk provides strong near-term signals for downside risks to growth (figure). The estimated impact of tighter price of risk appears stronger at the tails of the growth distribution than around the median, supporting the view of asymmetries in the output response. The price of risk becomes uninformative over longer horizons. In contrast, credit aggregates forecast downside risks to growth well over the medium term. This finding appears to be consistent with the volatility paradox (Brunnermeier and Sannikov 2014) and is line with other empirical studies (IMF 2017b).

The GaR framework suggests that the downside risks to Portugal's growth outlook seem to be contained at present; however, there are lingering medium-term vulnerabilities. These moderate nearterm risks to growth reflect compressed credit spreads and low volatility amid supportive monetary conditions. Nevertheless, a repricing of risks and other shocks could be amplified by the elevated levels of leverage and result in less favorable growth outcomes (see IMF 2018d for details). 


\section{Box 2. Case Study: 2018 Article IV Consultation with Portugal (continued)}

The price of risk appears to provide the most powerful short-term signal, whereas credit aggregates are the most significant predictor of future growth over the medium term.

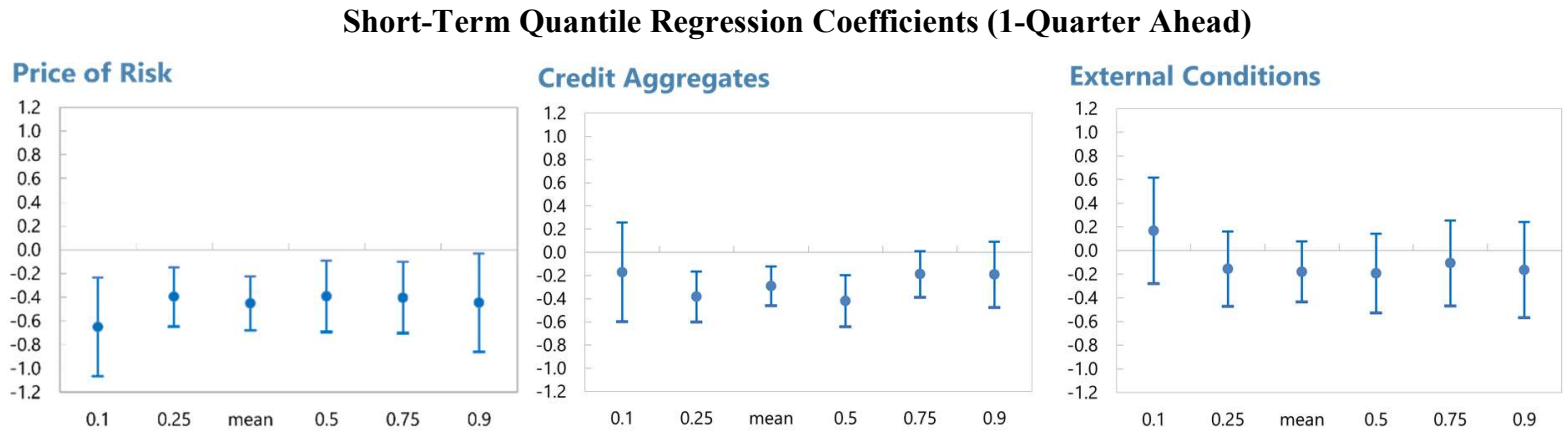

\section{Medium-Term Quantile Regression Coefficients (12-Quarters Ahead)}
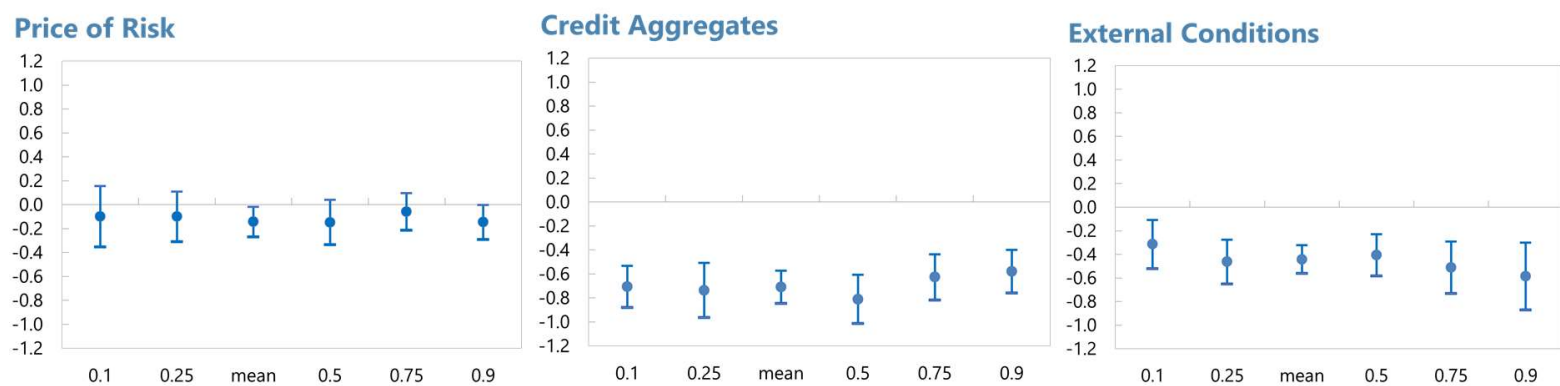

Source: Authors' calculations.

Note: The dots denote standardized quantile regression coefficients for the 10th, 25th, 50th, 75th, and 90th percentiles along with the OLS coefficients (mean), whereas the bars denote the 90 percent confidence intervals. See IMF (2018d) for further details. 


\section{Box 3. Case Study: 2018 Article IV Consultation with Singapore}

The 2018 Singapore Article IV consultation featured GaR analysis. In a highly open economy like Singapore, macrofinancial developments can be affected by external financial conditions, especially in a globally integrated financial system. At the same time, other factors such as main trading partners' output growth are central to Singapore's macroeconomic dynamics, given its export-oriented economy.

The GaR application in Singapore used a country-specific financial conditions index (FCI) to derive one-year-ahead growth distribution. This specialized FCI summarized information from 17 financial variables, including price-based, leverage-based, external, and other indicators, thereby combining elements that capture the price of risk and selected macrofinancial vulnerabilities. Historically, tighter financial conditions have been associated with a decline in real GDP growth in the near term (figure, top left panel).

External financial conditions, leverage-based indicators, and domestic price-based indicators explain most of the FCI fluctuations. Major events such as the Asian financial crisis (1997-98) and the global financial crisis (2007-09) are clearly reflected by a sharp tightening of Singapore's FCI (figure, top right panel). In addition, other episodes such as the European sovereign debt turmoil (2011-2012) and the "taper tantrum" (2013) are noticeable. These findings reflect the significant presence of international banks and the central role of Singapore in channeling cross-border capital flows in Southeast Asia.

The model was further augmented by housing market indicators and China's growth rate, which provide additional predictive power. GaR analysis tailored to Singapore suggests reduced tail risks in 2018 compared to 2017. The left tail of the growth distribution was fatter in 2017, and the recession probability was larger compared to 2018 (figure, bottom left panel). Specifically, the 5 percent GaR shows less cause for concern, improving from -2 percent at end-2017 to -0.7 at end-2018. The probability of recession declined from about 15 percent in 2017 to 8 percent in 2018, below its historical average (figure, bottom right panel). Different model specifications point to similar conclusions, with comparable patterns in terms of the recession probability forecast (for further details, see IMF 2018e).
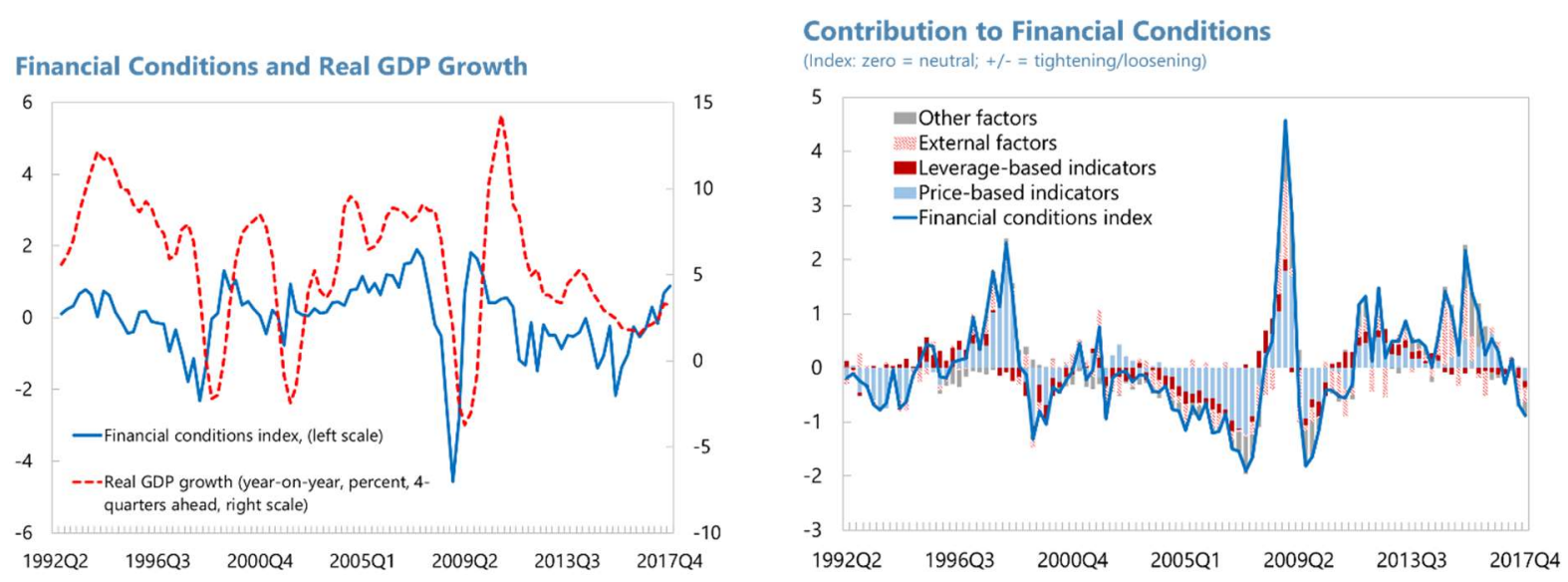


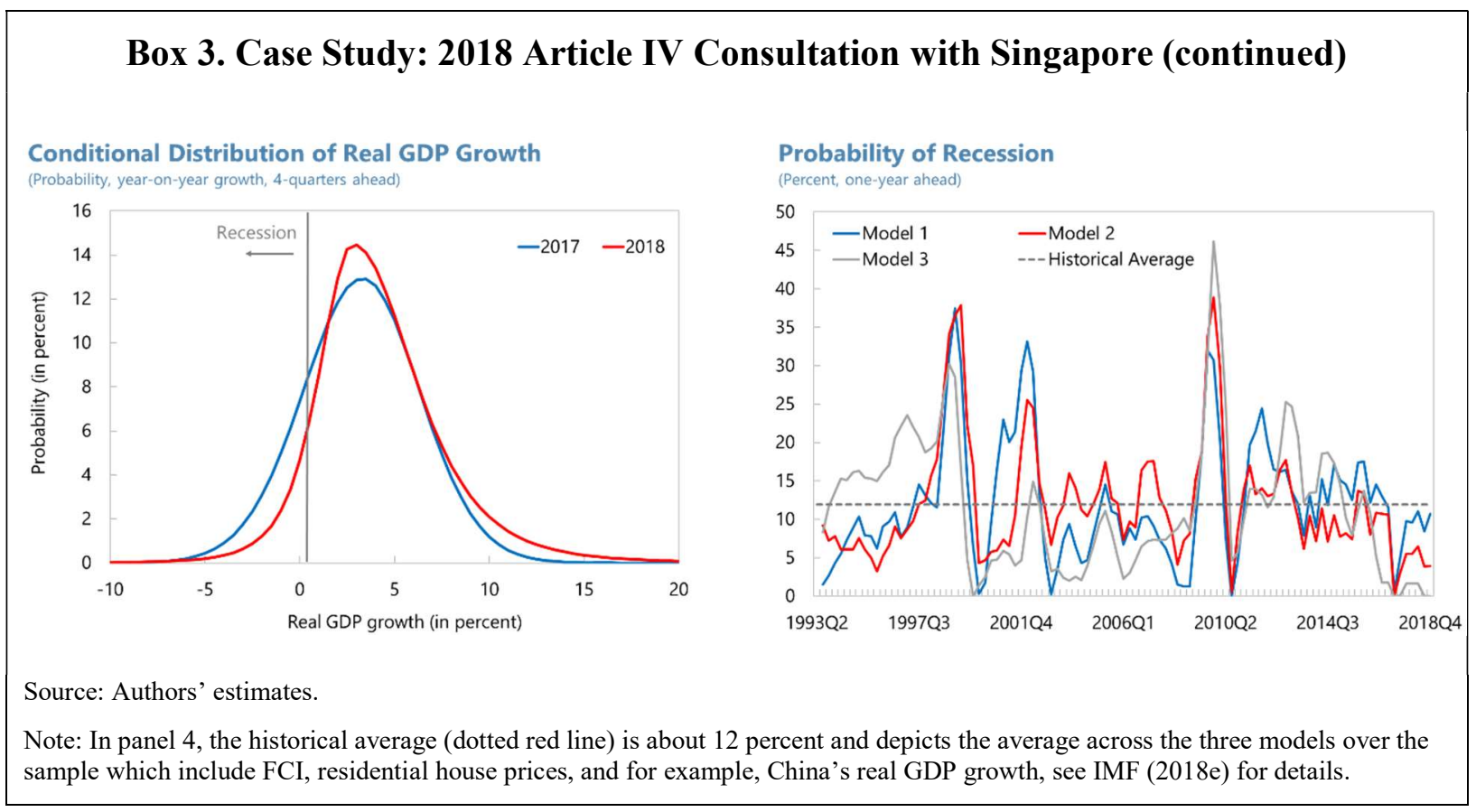

\section{Practical Guidance on How to Conduct Growth-at-Risk Analysis}

This section offers practical guidance on how to conduct GaR analysis, drawing on some early lessons from its use in Fund's bilateral macrofinancial surveillance. Using selected country cases, this section reviews the main features of an Excel-based GaR tool.

GaR analysis can be implemented in three main steps. All these steps can be performed by the user-friendly Excel-based tool developed by the IMF's Monetary and Capital Markets Department (MCM) in collaboration with the Information Technology Department (ITD). The first step is to select relevant macrofinancial variables and group them into partitions. The second step is to run quantile regressions and establish the relationship between future GDP growth and prevailing macrofinancial conditions. The third step is to derive the conditional distribution of future GDP growth.

Selected applications of GaR analysis are showcased throughout this section. The applications are based on country cases, some of which are ongoing. The analysis has been or can be readily carried out using the Excel-based GaR tool. The applications presented in this section cover the three main steps of the GaR framework and provide examples of scenario analysis. 


\section{A. Step 1: Selecting Macrofinancial Variables and Constructing Partitions}

The first step for conducting GaR analysis is to select macrofinancial variables and group them into partitions. The growth distribution derived under the GaR framework is underpinned by the prevailing macrofinancial conditions, and the results could vary significantly depending on the choice of selected macrofinancial variables. Potentially, many variables appear relevant for explaining the dynamics of GDP growth, but they tend to comove with one another in part because they reflect similar macrofinancial phenomena. Using partitions, instead of individual variables, help extract common trends among relevant macrofinancial variables and remove idiosyncratic noise, thereby improving the quality of the subsequent quantile regressions. ${ }^{13}$

It could be useful to categorize macrofinancial variables into several broad partitions. Country applications have benefitted from three broad partitions capturing (1) financial conditions, (2) macrofinancial vulnerabilities, and (3) other factors. ${ }^{14}$ The idea is to group macrofinancial variables into partitions of economic similarity. Although there is no single way to construct partitions, those listed above represent three intuitive, distinct economic concepts, that can be tailored to country-specific circumstances. ${ }^{15}$ The use of partitions generalizes the approach employed by earlier work in the GFSR (IMF 2017a), which only considers financial condition indices (FCIs). For example, with the inclusion of a macrofinancial vulnerabilities partition, the GaR analysis has the potential to shed further light on macrofinancial linkages and better signal systemic risks.

Once constructed, the indicators most relevant for each partition can be determined. There are many ways to construct partitions. When using principal component analysis (PCA) to extract common trends from a large array of indicators, the accompanying PCA factor loadings provide information about the relative importance of variables considered in each

\footnotetext{
${ }^{13}$ The cross-correlation of financial variables tends to be low in normal time but could increase significantly during bubbles and/or crashes_ _ periods when large amplification effects of financial conditions on economic activity are typically observed. Note also that using partitions reduces the number of parameters that need to be estimated, thereby helping overcome the potential challenge of limited data availability.

14 The use of the first two partitions is in line with Adrian and others (2019a) where an important distinction is made between (financial) shocks and macrofinancial imbalances which develop endogenously and act as potential amplifiers of shocks.

${ }^{15}$ Additional partitions should be considered if certain variables exhibit distinctive dynamics that appear useful for explaining economic prospects. If, for example, domestic and external demand measures are highly asynchronous, it may be useful to include two separate partitions to capture macroeconomic developments. In the context of principal component analysis (PCA), an additional partition would be warranted if a second principle component provides additional information content that is significantly relevant for the analysis. As discussed in greater detail later, for (lower-income) countries with relatively illiquid financial markets, nonfinancial factors (such as commodity prices, FDI flows, and growth in main trading partners) may be especially relevant for future growth dynamics.
}

(continued...) 
partition. An assessment of whether the partitions of macrofinancial variables are sensible should be made. Importantly, GaR analysis could be sensitive to the choice of variables and methodologies employed. ${ }^{16}$

The financial conditions partition aims at capturing the price of risks embedded in asset prices, the ease of obtaining financing, the cost of funding, and the degree of financial stress. For major advanced economies, a variety of FCIs have been produced to capture some or all abovementioned aspects. These FCIs could be directly used as a partition in the GaR analysis. For other economies, a partition of financial conditions may need to be constructed. The GFSR presented methodologies for constructing FCIs (IMF 2017a, IMF 2017b). Table 1 presents an illustrative, rather than comprehensive, list of variables that could be used for constructing the financial conditions partition (see also Arregui and others, 2018).

\section{Table 1. List of Potential Variables Representing Financial Conditions}

\begin{tabular}{|c|c|c|c|}
\hline $\begin{array}{c}\text { Price of risks } \\
\text { embedded in asset } \\
\text { prices }\end{array}$ & $\begin{array}{l}\text { Ease of obtaining } \\
\text { financing }\end{array}$ & Cost of funding & $\begin{array}{l}\text { Degree of financial } \\
\text { stress }\end{array}$ \\
\hline $\begin{array}{l}\text { - Term premiums } \\
\text { - Interbank spreads } \\
\text { - Corporate bond } \\
\text { spreads } \\
\text { - Sovereign bond } \\
\text { yield spreads (within } \\
\text { currency union, } \\
\text { relative to "safe- } \\
\text { haven" assets) } \\
\text { - Bond returns } \\
\text { - Bond return } \\
\text { volatility } \\
\text { - Equity returns } \\
\text { - Equity return } \\
\text { volatility }\end{array}$ & $\begin{array}{l}\text { - Bank lending } \\
\text { standards (based on } \\
\text { surveys) } \\
\text { - House price growth }\end{array}$ & $\begin{array}{l}\text { - Real long-term } \\
\text { interest rates, } \\
\text { including } \\
\text { government bond } \\
\text { yields, mortgage } \\
\text { rates, and prime } \\
\text { business lending } \\
\text { rates } \\
\text { - Cost of U.S. dollar } \\
\text { funding }\end{array}$ & $\begin{array}{l}\text { - VIX } \\
\text { - Foreign exchange } \\
\text { market pressures, } \\
\text { capturing exchange } \\
\text { rates, foreign } \\
\text { reserves, and short- } \\
\text { term interest rates } \\
\text { - Probability of } \\
\text { default of financial } \\
\text { institutions (based } \\
\text { on CDS spreads or } \\
\text { contingent claims } \\
\text { analysis) }\end{array}$ \\
\hline
\end{tabular}

\footnotetext{
${ }^{16}$ Naturally, data quality and availability impact the ensuing analysis. It is important to note that the partitions may not necessary be uncorrelated. This is because each partition is constructed using, for example, the first principal component. Although (dynamic) factor models can be employed, the economic interpretation of the factors may not be intuitive.
} 
The set of indicators that properly reflect financial conditions is likely to differ across countries. For advanced economies with deep and sophisticated financial markets, the price of risk embedded in asset prices would likely provide useful information about the state of the financial system. For emerging market and developing economies, the cost of U.S. dollar funding could matter significantly given their dependence on foreign-currency and external funding. Furthermore, indicators that capture foreign exchange market pressures would be useful to capture episodes of sudden stops of capital flows. For bank-dominated financial systems, bank lending rates to firms and households and bank lending standards would be a significant component of financial conditions. For economies with large mortgage debt, house prices, which affect collateral value of mortgage borrowing, would matter. For small open economies, global financial conditions could have a material impact on domestic financial conditions, thereby warranting the inclusion of a global FCI (Box 4).

\section{Box 4. Constructing a Financial Conditions Partition}

This box provides an example of how to select macrofinancial variables to construct a financial conditions partition based the case of a small, open advanced economy.

In this country case, the financial conditions partition is constructed to capture several underlying concepts: (1) the price of risk, (2) the ease of obtaining financing, (3) the cost of funding, and (4) global financial conditions. The price of risk comprises interbank spreads, term premiums, interbank spreads, bond returns, bond returns volatility, equity returns, and equity returns volatility; the ease of obtaining financing consists of bank lending standards and house price growth; the cost of funding is proxied with real long-term interest rates; and global financial conditions are captured using the global financial conditions index (FCI) used in IMF (2017b).

The inclusion of the global FCI appears to influence the profile of the financial conditions partition. Without the global FCI, the partition based on purely domestic indicators suggest slightly tighter financial conditions during the early 1990s, but a less abrupt tightening during the global financial crisis (figure, left panel). Although these differences are not stark, it is important to carefully examine the estimated partitions to ensure that they reflect historical developments as accurately as possible.

Global financial conditions, equity and bond return volatility, as well as lending standards appear to be the main drivers of domestic financial conditions. The relative importance of the underlying variables contained in the financial conditions partition is determined by the PCA factor loadings (figure, right panel). 


\section{Box 4. Constructing a Financial Conditions Partition (continued)}

The inclusion of global financial conditions could make a difference.

Financial Conditions Indices

(Index)

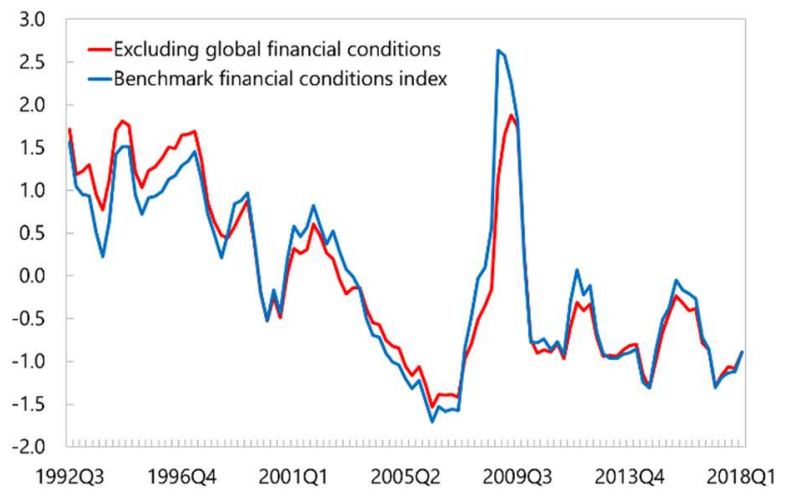

Global financial conditions and equity return volatility are among the most influential drivers of financial conditions.

Relative Importance of Underlying Indicators:

Financial Conditions Partition

(Relative importance based on PCA loadings)

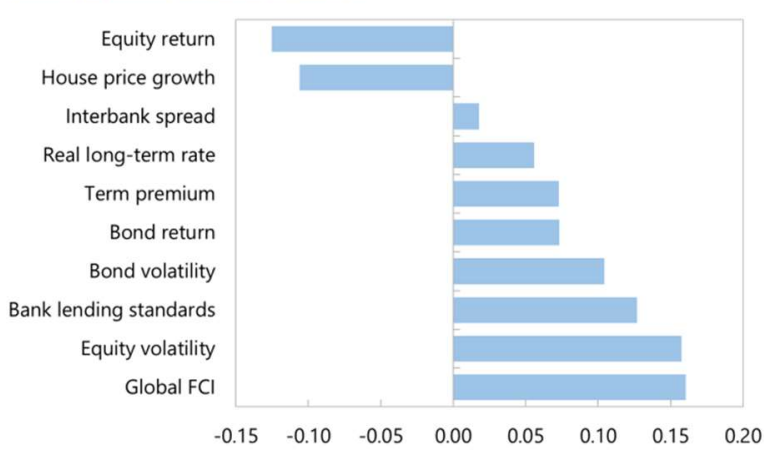

Source: Authors' estimates.

Note: PCA refers to principle component analysis. "Global FCI" refers to a global financial conditions index which is defined as the first principal component of the country-level FCIs (capturing both the price of risk and leverage dynamics, among others) as discussed in IMF (2017b).

The macrofinancial vulnerabilities partition should capture macrofinancial imbalances and sectoral balance sheet weaknesses. The indicators selected will vary across countries. The macrofinancial vulnerabilities partition is conceptually broader than a set of credit aggregates (such as credit growth and the credit-to-GDP gap). In addition to credit boom-bust cycles, macrofinancial imbalances could potentially emerge in the housing market and in the external sector. Sectoral balance sheet weaknesses of corporates, households, and governments (both central and regional) could also be relevant, and multifaceted aspects such as leverage, liquidity, debt servicing capacity, and indebtedness should be considered. Balance sheet weaknesses of financial institutions, particularly of banks, could also matterespecially when banks hold thin capital buffers, generate weak profitability, and rely on short-term, volatile funding sources. These indicators are typically part of systemic risk monitoring, as developed in the extensive literature on early warning indicators. Likewise, indicators of macrofinancial vulnerabilities form a typical set of indicators relevant for monitoring systemic risk and calibrating macroprudential policy (see IMF, 2014). ${ }^{17}$ Table 2

\footnotetext{
${ }^{17}$ Therefore, GaR analysis can evaluate the severity of systemic risk - possibly attributable to increasing macrofinancial vulnerabilities - and its implications for growth. Likewise, the GaR framework is promising as a means to quantify the intertemporal tradeoff associated with a tighter macroprudential policies (an area for future research). Specifically, although a tighter stance could result in slightly subdued economic activity in the short term, it could lower medium-term risks to the growth outlook owing to reduced macrofinancial vulnerabilities.
} 
outlines an illustrative, rather than exhaustive, list of variables that could be used for constructing the partition of macrofinancial vulnerabilities, and Box 5 provides an example.

Table 2. List of Potential Variables Representing Macrofinancial Vulnerabilities

\begin{tabular}{|c|c|}
\hline Macrofinancial imbalances & Indicators \\
\hline Credit boom-bust cycles & $\begin{array}{l}\text { - Credit-to-GDP gap } \\
\text { - Credit growth }\end{array}$ \\
\hline Housing market imbalances & $\begin{array}{l}\text { - House prices relative to fundamentals (income or rent) } \\
\text { - House price growth } \\
\text { - Growth of construction activity (such as construction } \\
\text { investment, residential permit value, dwelling starts, } \\
\text { dwelling under construction, and housing completion) } \\
\text { - Housing inventory } \\
\text { - Sales to new listings } \\
\text { - Growth of residential mortgage }\end{array}$ \\
\hline External imbalances & $\begin{array}{l}\text { - External debt or net foreign liabilities } \\
\text { - Current account deficit } \\
\text { - External financing need; external financing gap }\end{array}$ \\
\hline $\begin{array}{c}\text { Borrowers' sectoral balance sheet } \\
\text { weaknesses }\end{array}$ & Indicators \\
\hline Corporate & $\begin{array}{l}\text { - Leverage: liabilities to assets } \\
\text { - Debt servicing capacity: interest coverage ratios } \\
\text { - Indebtedness: debt to GDP } \\
\text { - Currency mismatch }\end{array}$ \\
\hline Household & $\begin{array}{l}\text { - Leverage: liabilities to assets } \\
\text { - Debt servicing capacity: interest coverage ratios } \\
\text { - Indebtedness: debt to GDP; debt to income } \\
\text { - Currency mismatch }\end{array}$ \\
\hline Government & $\begin{array}{l}\text { - Fiscal financing need; fiscal financing gap } \\
\text { - Indebtedness: debt to GDP }\end{array}$ \\
\hline $\begin{array}{l}\text { Financial sector balance sheet } \\
\text { weaknesses }\end{array}$ & Indicators \\
\hline Bank & $\begin{array}{l}\text { - Solvency and leverage: capital adequacy ratios; equity to } \\
\text { assets } \\
\text { - Liquidity and funding: short-term liabilities to liquid assets; } \\
\text { stable funding to total funding } \\
\text { - Profitability and viability: return on assets; return on equity }\end{array}$ \\
\hline
\end{tabular}




\section{Box 5. Example of Macrofinancial Vulnerabilities Partition}

This box provides an example of how to select macrofinancial variables for constructing a partition of macrofinancial vulnerabilities based on a small, open advanced economy.

In this example, the macrofinancial vulnerabilities partition is constructed using three underlying aggregates and the credit-to-GDP gap. These aggregates attempt to capture (1) household sector vulnerabilities, (2) corporate sector vulnerabilities, and (3) housing market imbalances. The measures capturing household and corporate sector vulnerabilities are aggregated from indicators that capture leverage, debt servicing capacity, and indebtedness. Housing market imbalances are aggregated from indicators that measure imbalances from multiple aspects, including house price dynamics, construction activity, inventory and sales, mortgage activity, and household financial strength.

Two approaches are used to estimate the aggregates which underpin the overall macrofinancial vulnerabilities partition. The first approach utilizes principal component analysis, while the second approach simply aggregates indicators and standardizes them. The two methodologies yield different time series patterns (figure). In particular, corporate sector vulnerabilities exhibit starkly different dynamics during the early 1990s. Naturally, the choice of approach used would influence the subsequent steps of the GaR analysis.

The household sector appears to influence the dynamics of the overall macrofinancial vulnerabilities partition to the greatest extent. Factor loadings from principal component analysis indicate that the household and corporate sector aggregates as well as the credit gap measure are the most important drivers of the macrofinancial vulnerabilities partition. 


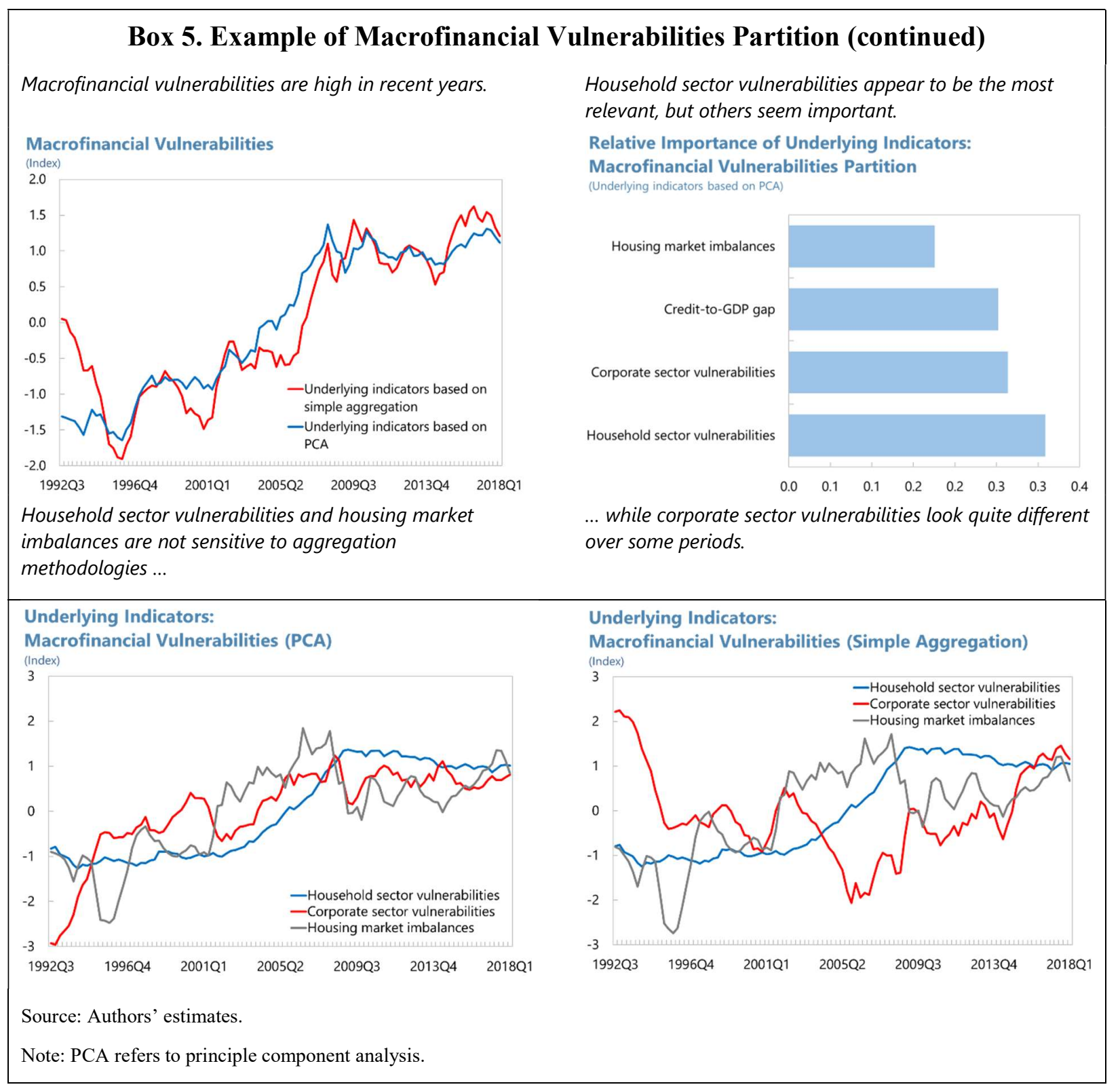

Factors other than financial conditions and macrofinancial vulnerabilities are also likely to be relevant for explaining future growth dynamics. The other factors partition could attempt to reflect external and domestic conditions. Measures of external demand (for example, major trading partners' growth or global growth) and commodity prices are likely to influence growth prospects. Domestic factors such as consumer confidence, business sentiment, and policy uncertainty tend to significantly affect near-term growth dynamics. More broadly, this partition should include risk factors that are relevant in the RAM (which have not been accounted for by the financial conditions and macrofinancial vulnerabilities partitions). Box 6 provides an example of such a partition. The box also draws attention to the 
importance of the proper alignment of forecasting horizons between future GDP growth and relevant macroeconomic drivers.

\section{Box 6. Example of an "Other Factors" Partition}

Factors other than financial conditions and macrofinancial vulnerabilities can impact future growth. This box provides an example of an "other factor" partition for a small, open advanced economy. In this country case, the "other factors" partition is constructed based on U.S. growth, China's growth, and commodity prices (both energy and non-energy commodities). The factor loadings based on PCA suggest that commodity prices appear more important than the economic activity of key trading partners in terms of explaining future growth fluctuations (figure, left panel).

An important caveat has to do with ensuring that forecasting horizons are properly aligned.

Although forecasts of trading partner growth, for example, can be closely synchronized with future GDP growth (figure, right panel), using the current values of trading partner growth could result in a negative correlation. A lack of consistency between the horizon of future growth and the projections of the other factors would then distort the ensuing regression analysis. Therefore, applications should ensure that the alignment of forecasting horizons for future GDP growth and relevant other factors are similar.

Commodity prices are examples of other factors that have a bearing on future growth...

Relative Importance of Indicators in the Other Factors Partition

(Underlying indicators based on PCA)

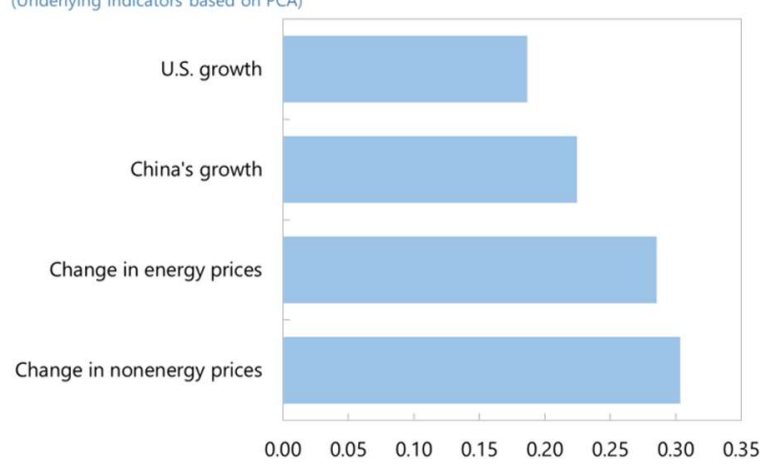

Source: Authors' estimates.

Note: PCA refers to principle component analysis. ...note, however, that such factors are synchronized with future real GDP growth.

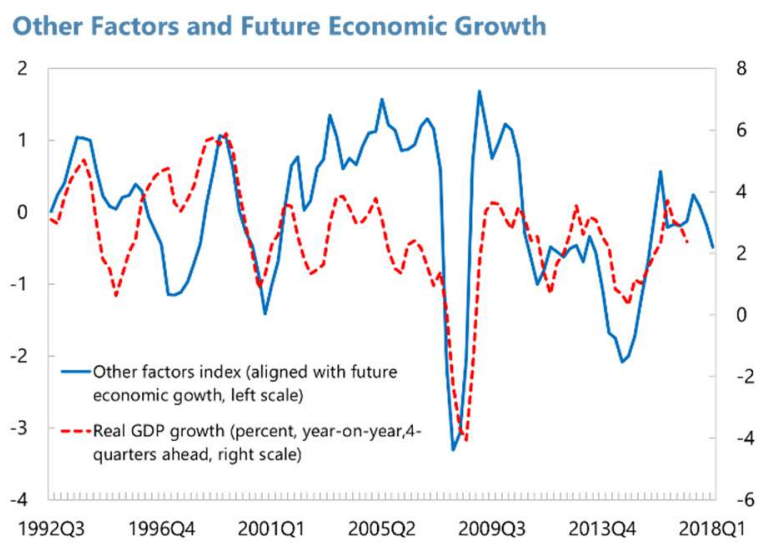

\section{B. Step 2: Quantile Regression Estimation}

The second step of GaR analysis involves the estimation of quantile regressions. Quantile regressions are used to estimate the potentially nonlinear relationship between selected explanatory variables (such as the financial conditions and macrofinancial vulnerabilities 
partitions) and quantiles of future GDP growth. ${ }^{18}$ Conceptually, a quantile regression at the $10^{\text {th }}$ percentile would estimate a relationship when growth is relatively weak, while a quantile regression at the $90^{\text {th }}$ percentile would be based on stronger growth outcomes. It is important to recognize the estimated coefficients are likely to differ across quantiles and for different horizons.

Depending on the objective of the GaR application, choices need to be made regarding how growth is calculated and the length of the forecasting horizon:

- The quantile regressions can be based on year-on-year growth rates or cumulative change in real GDP. ${ }^{19}$ The former is suitable in the context of IMF Article IV consultations in part because it aligns with World Economic Outlook (WEO) standards. The latter may more usefully guide stress testing scenario design, where cumulative growth rates are more appropriate for evaluating the severity of the adverse scenarios over the stress testing horizon.

- $\quad$ The GaR analysis appears capable of assessing risks to future GDP growth reasonably well up to 12 quarters ahead in many countries. ${ }^{20}$ Applications focusing on near-term risks may consider shorter horizons, while those investigating medium-term prospects might choose longer horizons. Naturally, the frequency of the data would affect the length of the horizon chosen.

The relationship between the macrofinancial factors and future GDP growth tend to vary over the forecasting horizon. Intuitively, tight ("high") financial conditions are likely to suppress economic activity in the coming quarters, resulting in a negative correlation in the near term. However, financial conditions will eventually revert to their historical averages. This normalization of financial conditions would then boost growth a few years down the road, yielding a positive correlation between current financial conditions and future growth. In contrast, when macrofinancial vulnerabilities are elevated, risks to economic activity would be high, not only in the near term, but also over the medium term. In this case, there would be an inverse relationship between future GDP and macrofinancial vulnerabilities across all forecasting horizons (Box 7). At the same time, it is important to recognize that although accommodative financial conditions can stimulate near-term economic activity, such conditions induce a buildup of vulnerabilies, which raise medium-term risks to the economic outlook.

\footnotetext{
${ }^{18}$ See Koenker (2005) for a more complete introduction on the quantile regression estimation.

${ }^{19}$ A year-on-year growth projection that is h-quarters ahead is defined as a change over a period of four quarters leading to h-quarters ahead. A cumulative growth projection is defined as a change between the starting point and the h-quarters ahead. Note that year-on-year growth and cumulative (annualized) growth are identical at 4quarters ahead.

${ }^{20}$ See, for example, IMF (2017b).
} 
Quantile regression estimation can uncover nonlinear relationships between the growth outlook and prevailing macrofinancial conditions that are state dependent. Estimating the lower (upper) quantiles attempts to capture how current macrofinancial factors influence future growth when the outlook is relatively bleak (favorable). Such information could be particularly useful for policymakers. If policymakers know that tight financial conditions will likely have a much larger negative impact on economic activity when the near-term growth outlook is already dim, then they may wish to employ accommodative policy measures more proactively than when the growth outlook remains favorable. Likewise, rising macrofinancial vulnerabilities may have larger adverse effects on economic activity when growth is subdued, which could reflect how these elevated vulnerabilities amplify the impact of shocks (Box 7).

It is important to acknowledge the data requirements for robust $\mathrm{GaR}$ analysis. Note that the country case studies discussed earlier are based on quarterly data starting in the early 1990s. While sufficiently long time series would most likely improve estimation precision, the nature of the data also matters a great deal. This is particularly relevant for quantile regressions, where a greater number of business and financial cycle fluctuations (including some tail events) would refine the accuracy of the estimated parameters. ${ }^{21}$

\section{Box 7. Example of Quantile Regression Estimation}

This box provides an example of how quantile regressions are used to estimate the relationship between future GDP growth and prevailing financial conditions and macrofinancial vulnerabilities for a small, open advanced economy.

In this example, a set of parsimonious quantile regressions are utilized to forecast future growth conditional on a financial conditions partition and a macrofinancial vulnerabilities partition while controlling for current growth. The quantile regressions are estimated across different quantiles (including the $10^{\text {th }}, 25^{\text {th }}, 50^{\text {th }}, 75^{\text {th }}$, and $90^{\text {th }}$ percentiles) and over selected forecasting horizons. The quantile regression takes the following specification:

$$
y_{t+h}^{q}=\alpha^{q}+\beta_{F}^{q} X_{F, t}+\beta_{V}^{q} X_{V, t}+\beta_{G}^{q} X_{G, t}+\varepsilon_{t+h}
$$

where $X_{F, t}, X_{V, t}, X_{G, t}$ represent the partitions of financial conditions, macrofinancial vulnerabilities, and contemporaneous real GDP growth (as a control), respectively. This box focuses on the estimated coefficients $\hat{\beta}_{F}^{q}$ and $\hat{\beta}_{V}^{q}$ at different quantiles (denoted with $q$ ), and for different forecasting horizons $(h=4,8)$.

\footnotetext{
${ }^{21}$ Along with the challenge of limited data availability (length and breadth), quantile regression analysis will be hampered when, for instance, FCIs do not accurately capture the dynamics of the financial system. For example, the price of risk partition may not be an informative indicator amid illiquid financial markets. Note that the Excel-based tool includes visual and quantitative diagnostics to help assess the sensitivity of the results (including quantile coefficients, standard errors, and R-squared metrics). The tool also uncrosses the predicted quantiles when needed, and therefore guarantees that the empirical quantile function is monotonous.
} 


\section{Box 7. Example of Quantile Regression Estimation (continued)}

Although the short- and medium-term relationship between financial conditions and future growth differ, in this example growth prospects and macroeconomic vulnerabilities are negatively correlated regardless of the forecasting horizon. For the four-quarters-ahead forecasting horizon (figure, top left panel), a tightening of financial conditions would represent a significant downside risk to growth when growth is very weak (lower quantiles). But it also poses an upside risk when growth is stronger (upper quantiles) - possibly related to a potential tightening of monetary policy amid a robust economic upswing. For the eight-quarters-ahead horizon, tighter financial conditions today are positively correlated with economic activity tomorrow (figure, top right panel). This may reflect that the current tightness of financial conditions will likely reverse, thereby bolstering future growth. Regarding macrofinancial vulnerabilities, the quantile regressions reveal that festering macrofinancial vulnerabilities represent downside risks to growth regardless of the forecasting horizons.

Tighter financial conditions are associated with lower (higher) growth over the next year when economic activity is relatively weak (strong).

Financial Conditions: 4-Quarters Ahead

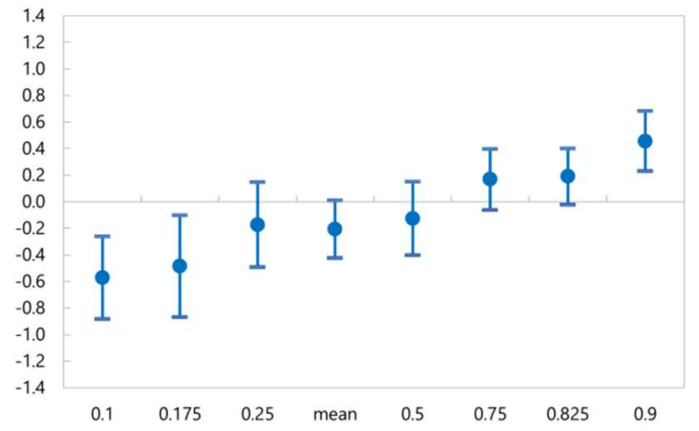

More elevated macrofinancial vulnerabilities are generally associated with weaker growth regardless of the horizon...

Macrofinancial Vulnerabilities: 4-Quarters Ahead

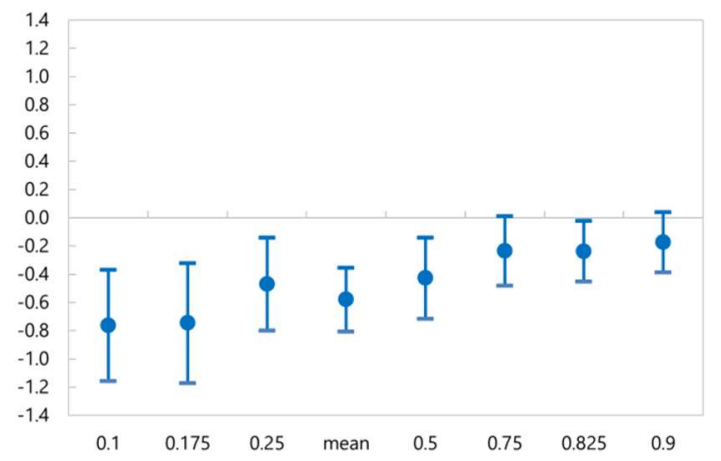

Tighter financial conditions are generally associated with stronger growth over a two-year horizon.

Financial Conditions: 8-Quarters Ahead

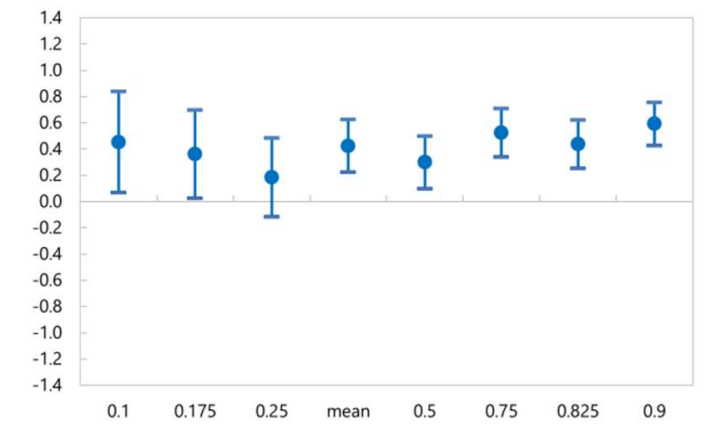

...but the impact of potential shock amplification is larger when two-year-ahead growth is weaker.

Macrofinancial Vulnerabilities: 8-Quarters Ahead

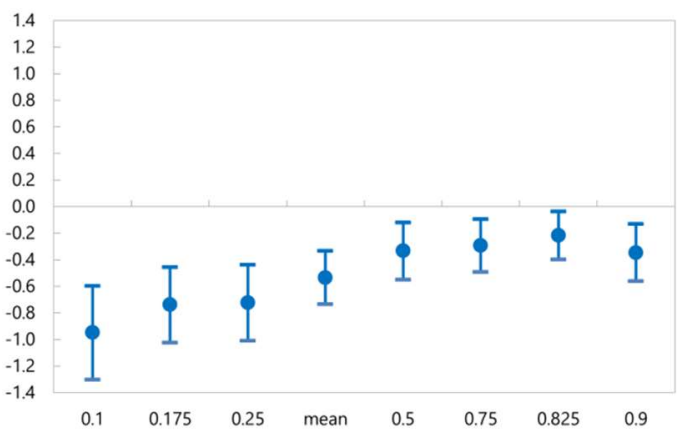

Source: Authors' calculations.

Notes: The dots and the bars denote the regression coefficient estimates and 90 percent confidence intervals, respectively. Mean denotes the coefficient from a regression based on ordinary least squares. Forecasts over 4 and 8 quarters are depicted $(h=4,8)$. 


\section{Step 3: Deriving the Conditional Future Growth Distributions}

The third step of GaR analysis entails the generation of the future growth distributions. After the quantile regression estimation based on partitions of macrofinancial variables, the conditional distribution of future GDP growth is derived by fitting a t-skew distribution to predicted values of the estimated conditional quantiles regressions following the approach advocated by Adrian, Boyarchenko, and Giannone (forthcoming). The complete distribution of future GDP growth conditional on the state of the macrofinancial environment enables an assessment of the likelihood of future economic activity at any level. Moreover, country economist's projections, for example, can be imposed to evaluate their realism relative to the unstrained conditional future growth distribution. The tool can also compute GaR estimates for different quantiles over time, thereby providing an assessment of the evolution of downside or upside risks to economic activity. More concretely, the tool can generate the probability of a recession over time.

\section{Assessing the Plausibility of Baseline and Alternative Scenarios}

In the Article IV context, GaR analysis can help assess whether a scenario is too optimistic or pessimistic. ${ }^{22}$ Consider a baseline distribution centered around a country economist's projection. This baseline distribution can be contrasted with another distribution based on an alternative growth projection to shed light on the attendant risk implications. ${ }^{23}$ For example, a more optimistic (pessimistic) forecast would be associated with relatively greater negative (positive) skew, indicating more elevated downside (upside) risks, as discussed in Box 8 . Such application can be particularly useful for appraising the plausibility of central and alternative scenarios, especially in the context of Article IV consultations. ${ }^{24}$

In the FSAP context, GaR analysis can help guide the design of macrofinancial scenarios for the stress testing exercise. The FSAP typically selects the severity of adverse scenarios based on historical volatility of real GDP growth. Usually, adverse scenarios would feature cumulative real GDP growth that is two standard deviations below the cumulative GDP

\footnotetext{
${ }^{22}$ This section focuses on scenario analysis and not the appraisal of density forecasts. Unlike the evaluation of point forecasts, the actual density is never observed — only a single draw from that density is available. Given this underlying challenge, the literature has developed various approaches to evaluate density forecasts: (1) by testing for the correct specification of the sequence of conditional densities using the probability integral transform (see, for instance, Diebold, Gunther, and Tay, 1998) and (2) by comparing density forecasts by examining differences in error losses, usually through density scoring (see, for example, Amisano and Giacomini, 2007). Although density forecast appraisal is beyond the scope of the current version of the tool, it is envisaged that future versions of the tool will include density forecast evaluation metrics.

${ }^{23}$ Note that imposing a mode (central projection) implies a constraint when fitting the t-skew distribution. See Appendix and Lafarguette (2019) for further details.

${ }^{24}$ In contrast to other approaches, GaR-based fan charts are appealing because they are conditional on current macrofinancial conditions, potentially asymmetric, and, for instance, allow for fat-tailed growth distributions. See also Elekdag and Kannan (2009) and, for example, Cornec (2014).
} 
growth in the baseline scenario. Such an adverse scenario is expected to occur once every twenty years on average. With the ability to quantify the likelihood of future GDP growth, $\mathrm{GaR}$ analysis can provide an alternative benchmark for evaluating the severity of adverse scenarios. The GaR approach also has an additional advantage as it can account for existing macrofinancial vulnerabilities. In particular, a more severe scenario will likely materialize when macrofinancial vulnerabilities are more elevated.

\section{Box 8. Examples of the GaR Analysis Outputs}

This box provides selected examples of outputs that the GaR tool can produce.

In this country case, the conditional growth forecasts are based on indices of financial conditions and macrofinancial vulnerabilities. The distribution of future GDP growth is derived by fitting a t-skew distribution to predicted values of the conditional quantile regressions. Consider a baseline distribution where a mode of 2.1 percent is imposed (which, for example, could reflect a country economist's projection). Under this baseline distribution, GaR at 5 percent is -0.7 , implying that there is a 5 percent chance that real GDP over the next 4 quarters will fall by at least 0.7 percent (figure, top left panel).

The tool can also be used to evaluate the realism of alternative future growth projections. Specifically, two different distributions are considered: the baseline of 2.1 percent and a more optimistic forecast with a mode of 4.1 percent ( 2 percentage points above the baseline). The negative skew of the distribution with the more optimistic mode signals that downside risks to future growth are more likely - the likelihood of real GDP growth being below 4.1 percent is 75 percent (figure, top right). Estimates of GaR computed over time suggest that the postcrisis risks to growth appear structurally higher relative to its precrisis average. At the onset of the global financial crisis, risks to growth shot up markedly amid a significant tightening of financial conditions (figure, bottom left panel). In particular, before the crisis, the estimate of GaR at 5 percent was about 0.4 percent, but then declined to about -1 percent in the postcrisis period. Since the crisis, risks to growth have remained elevated reflecting growing macrofinancial vulnerabilities (figure, bottom right panel). 


\section{Box 8. Examples of the GaR Analysis Outputs (continued)}

There is a 5 percent probability that real GDP growth will fall by at least 0.7 percent over the next four quarters.

Conditional Distribution of Real GDP Growth (Probability, year-on-year growth, 4-quarters ahead)

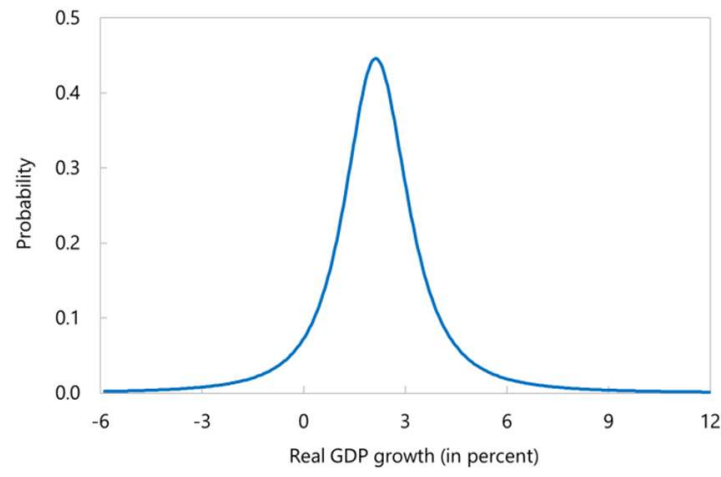

Risks to economic growth increased sharply during the global financial crisis and have remained elevated...

Real GDP Growth and Conditional Forecasts (Percent, year-on-year growth, 4-quarters ahead)
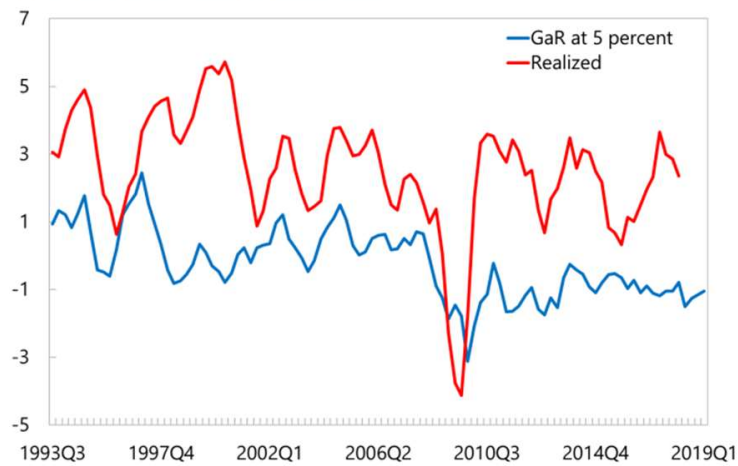

When the baseline looks too optimistic, downside risks to growth become more likely.

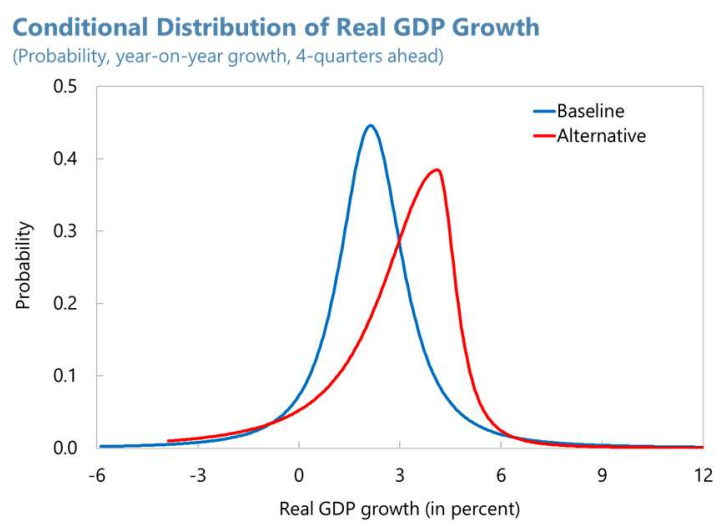

...reflecting mounting post crisis macrofinancial vulnerabilities.

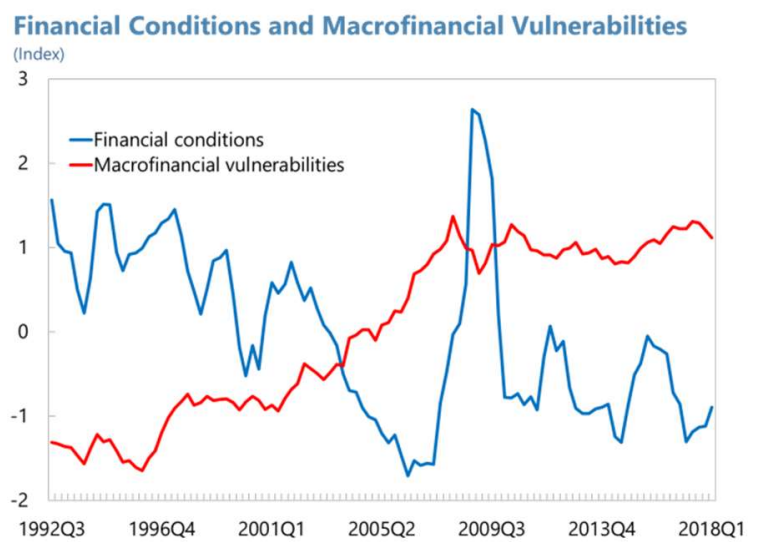

Source: Authors' calculations.

\section{E. Exploring the Effects of Risk Materialization}

The GaR framework enables scenario analysis. Specifically, the underlying macrofinancial conditions can be shocked to assess how the shape of the entire future growth distribution potentially changes. ${ }^{25}$ Such hypothetical scenarios provide policymakers with additional information about how the realization of a risk affects the distribution of growth in future periods. For instance, the probability of an economic contraction would most likely increase if financial conditions tighten, macrofinancial vulnerabilities continue to build up, and/or the macroeconomic environment becomes less favorable. Although shifts in some of the

${ }^{25}$ Given that the current GaR framework is a parsimonious reduced-form forecasting system, the scenario analysis is based on comparative statics analysis, which considers uncorrelated shocks without taking into account feedback. That said, multiple correlated shocks could be readily considered based on user-provided covariance structures. 
macrofinancial drivers of growth may affect the center of the distribution, other factors may influence the shape of the left tail—and thereby the likelihood of downside risks - to a much greater extent. Box 9 provides an example of scenario analysis.

\section{Box 9. Example of Scenario Analysis}

This box provides an example of how scenario analysis can be conducted with the GaR framework.

GaR can be used to shock selected macrofinancial variables to assess how the nature of tail risks change. Recall that although $\mathrm{GaR}$ is a flexible and parsimonious approach, it is also a reduced-form framework, and the scenarios considered here reflect comparative statics analysis. With the caveat in mind, consider a baseline future growth distribution, possibly centered around a country economist's projection (figure). GaR can be used to quantify the impact of a realization of a risk. For example, the impact of tighter global financial conditions on future growth is illustrated.

Notice how this shock reduces average future growth (in parallel with the leftward shift in the peak of the distribution). Moreover, the shape of the growth distribution changes, affecting the degree of skewness and, for example, the contour of the tails. In fact, under this alternative scenario, tighter global financial conditions would increase the probability of an economic contraction to 18 percent from 8 percent (the difference in these probabilities is indicated by the shaded area between the distributions).

Conditional Distributions of Real GDP Growth

(Probability, percent, year-on-year growth, 4-quarters ahead)

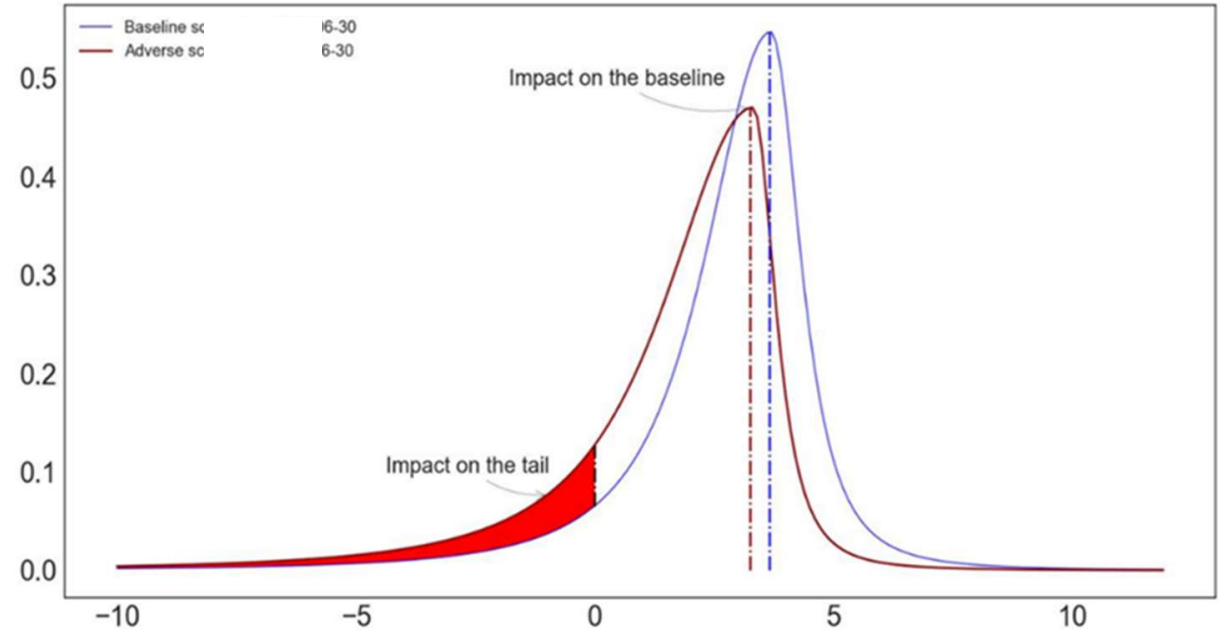

Source: Authors' calculations.

Note: The baseline distribution and its mode are indicated with the blue solid and dashed lines, respectively. The shocked distribution and its mode are indicated with the red solid and dashed lines, respectively. The shaded area between these distributions indicates how the probability of negative future growth increases. 


\section{Conclusion}

The growth at risk (GaR) framework is an insightful addition to the macrofinancial surveillance toolkit. Its foremost strength is its ability to quantify macrofinancial risks to growth, assess the relative importance of the macrofinancial factors that impact the entire probability distribution of future GDP growth, and monitor how risks to economic activity may evolve over time. By offering quantitative insights on the probability, impact, and the nature of risks to future growth, the GaR framework provides a basis for preemptive policies to mitigate downside risks. Furthermore, GaR analysis enables policymakers to better communicate the risks to growth to the public.

Given its potential, an Excel-based GaR tool has been developed to support the Fund's bilateral surveillance efforts. The tool can (1) compute country-specific FCIs and estimate tailored partitions of macrofinancial variables, (2) rank variables according to their informational content, (3) estimate quantile regression coefficients (over selected forecasting horizons and quantiles), (4) generates fitted future growth distributions (which can be centered on point forecasts in line with a country economist's projections), and (5) facilitate scenario analysis. In sum, the GaR tool can be flexibly customized to reflect country-specific risks and vulnerabilities.

The use of GaR analysis in the Fund's bilateral surveillance activities is relatively new. This paper has presented recent and ongoing applications of how the GaR framework can enrich policy discussions. GaR analysis has considerable potential, but the current parsimonious forecasting setup also has its limitations. GaR is not a structural model and, therefore, should not be used to make causal inferences. The data preconditions (length, breadth, cyclical variation) for robust GaR analysis also need to be recognized. Nevertheless, the GaR-based research agenda is making headway, and GaR-related methodologies will continue to evolve going forward. For example, in the spirit of Adrian and others (2018), who investigate GaR's term structure, GaR holds great promise as a framework for quantifing the intertemporal tradeoffs associated with, for instance, macroprudential policies. The GaR framework can be extended to encompass other variables as well as their interactions. Asset prices, returns, or valuation metrics can be used instead of growth. At the same time, future work could investigate multivariate systems whereby growth, financial conditions, and, for example, bank capital are considered jointly in an "at-risk" framework (Adrian and others, 2019b).

Although evaluating policy trade-offs is challenging, research by the IMF and some central banks is exploring how the GaR framework can support countries' macroprudential policy implementation. Indicators have been identified to monitor systemic risk and help calibrate macroprudential instruments, however macroprudential surveillance does not typically provide a probabilistic assessment of the potential impact of systemic risk on the real economy. The GaR framework fills this gap and provides an analytical framework for quantifying the severity of systemic risk based on the existing level of macrofinancial vulnerabilities. 


\section{Growth-at-Risk: Technical Appendix ${ }^{26}$}

\section{Overview}

This technical appendix presents an overview of the technical aspects related to conducting Growth-at-Risk (GaR) analysis (for further details, see Lafarguette 2019). The GaR empirical strategy is to estimate the future conditional growth distribution based on a parsimonious approach, involving data reduction, quantile regressions, and finally a parametric fit (to generate the future growth distribution).

\section{Step 1: Partitioning Macrofinancial Variables Using Dimensionality Reduction}

The first step of GaR analysis involves aggregating the set of macrofinancial variables into economically meaningful groups ("partitions"). In many applications, partitions such as the price of risk, macrofinancial vulnerabilities (for example, leverage), and other (external) factors were considered. These partitions can be computed using either principal component analysis (PCA) or, for instance, linear discriminant analysis (LDA). Though similar, LDA links financial variables with GDP growth during the dimensionality reduction process, while PCA only aggregates information about common trends among financial variables. Even though variables can be considered individually, partitioning has advantages, including that it often improves forecasting by extracting common trends in macrofinancial variables, hence filtering out idiosyncratic noise, which may be endemic in countries with illiquid markets.

\section{Step2. Quantile Regressions}

The dependent variable for the quantile regression analysis, real GDP growth, can be calculated in two different ways: either as an annualized quarterly compound growth rate between period $t$ and period $t+h$, where $h$ is the horizon defined by the user; or the year-onyear growth rate, $h$ periods ahead. For a set of horizons $h \in\{1, \ldots, 12\}$ where $h$ represents the quarters ahead, the following specifications are estimated:

$$
y_{t+h}^{q}=\alpha^{q}+\beta_{1}^{q} X_{1, t}+\beta_{2}^{q} X_{2, t}+\beta_{3}^{q} X_{3, t}+\varepsilon_{t+h}^{q}
$$

where $y_{t+h}^{q}$ represents future growth $h$ quarters ahead for quantile $q$, and where $q \in$ $\{0.1,0.25,0.5,0.75,0.9\} ; X_{1, t}, X_{2, t}, X_{3, t}$ represent three illustrative partitions (encompassing the price of risk, macrofinancial vulnerabilities, and other factors) with their associated coefficients, $\beta_{1}^{q}, \beta_{2}^{q}, \beta_{3}^{q}$; and $\alpha^{q}$ and $\varepsilon_{t+h}^{q}$ denote a constant term and the residual, respectively. The quantile regressions are estimated at different points of the distribution of $y_{t+h}^{q}$, and each coefficient, for example, $\beta_{1}^{q}$, represents the macrofinancial linkage between the variable $X_{1, t}$ and future growth, at different points of the future growth distribution.

\footnotetext{
${ }^{26}$ A more detailed technical appendix is available in the Github repository https://github.com/IMFGAR/GaR
} 


\section{Step 3: Parametric Fit of the Conditional Distribution of Future Growth}

\section{Conditional Quantiles}

Like an OLS regression provides an estimation of a conditional mean, quantile regression estimates conditional quantiles of the dependent variable $y_{t+h}^{q}$, conditional on financial variables $X_{i, t}, Q\left[y_{t+h}^{q}\right]$, for a given date $t$, based on the point estimates of the coefficients:

$$
Q\left[y_{t+h}^{q}\right]=\hat{\alpha}^{q}+\hat{\beta}_{1}^{q} X_{1, t}+\hat{\beta}_{2}^{q} X_{2, t}+\hat{\beta}_{3}^{q} X_{3, t}
$$

Using quantile regressions for estimating the conditional distribution has many advantages: first, under standard assumptions, quantile regressions provides the best unbiased linear estimator for the conditional quantile; second, quantile regressions are robust to outliers, which are frequent when dealing with countries with poor data coverage. Finally, the asymptotic properties of the quantile regression estimator are well-known and easy to derive.

\section{Parametric Fit}

The conditional quantiles are a sufficient statistic for describing the conditional cumulative distribution function (CDF). In this paper, following Adrian, Boyarchenko, and Giannone (forthcoming), a parametric t-skew fit is used to derive the probability distribution function from the CDF which is a skewed version of the $\mathrm{t}$-distribution (as in Azzalini and Capitanio 2003), and has many applications in finance. The t-skew distribution is fully characterized by four parameters (location, degree of freedom, scale, and skewness) and is thus a parsimonious, yet comprehensive way to summarize the information about the variance (volatility), skewness, and kurtosis contained in the sample.

\section{T-skew Distribution}

The standardized version of the t-skew function is as follows:

$$
F^{*,-1}(q \mid \alpha, d f, \xi)=\left(F^{-1}(q \mid \alpha, d f, \xi)-l o c\right) / \text { scale }
$$

where loc is the location (the mean) and scale the variance of the distribution.

\section{From the Empirical CDF to the T-skew Parameters}

To estimate the t-skew distributions, the parameters of interest are derived by minimizing the distance between the empirical quantiles and the quantiles of a t-skew: 


$$
\text { loc, scale, skew }=\operatorname{argmin}\left[\sum_{q}\left\{t s k . q u a n t i l e(q, \operatorname{loc}, d f, \text { scale, skew })-Q\left[y_{t+h}^{q}\right]\right\}^{2}\right]
$$

Where tsk. quantile ( $q, l o c, d f$, scale, skew) represents the quantile $q$ of the t-skew distribution with parameters (loc, df, scale, and skew). Once the optimal t-skew parameters have been estimated from the conditional quantiles, it is straightforward to derive the fitted tskew CDF and probability density function (PDF) which facilitate GaR analysis.

The t-skew distribution can be fit by constraining the location (the mode) of the distribution. This option is useful if (1) there is a more accurate forecast for the mode available or (2) to make the density forecast consistent with other point forecasts (for instance, a country economist's forecasts). In this case, the distribution fit must be optimized under the constraints, and not simply by translating the original distribution linearly as discussed in Lafarguette (2019).

Note that imposing the mode can have a large impact on the fitted t-skew distribution, in particular if the constrained location differs significantly from the unconstrained location corresponding to the conditional quantiles. In this case, the distribution will have to adjust its variance and skewness to meet the mode. As a result, an optimistic ad hoc mode, which is greater than the unconstrained mode, will result in inflated downside risks.

\section{Scenario Analysis}

It is also possible to conduct scenarios analysis, in a static way. Comparative static exercises can explore the impact on a shock of the raw variables on the future growth distribution. For example, using the estimated quantile regressions, the conditional quantiles based on the new

partition $\tilde{X}_{i, t}=X_{i, t} *(1+$ shock $)$ is re-estimated. Note that the estimated beta coefficients are the same as in the baseline regressions, hence ensuring that the scenarios are comparable. Based on the counterfactual quantiles, a new t-skew distribution is generated (with the possibility to have unconstrained and constrained modes). Shocks to individual variables underlying the partitions are also possible, as discussed in Lafarguette (2019). 


\section{References}

Adrian, T., E. Moench, and H. Shin. 2010. "Macro Risk Premium and Intermediary Balance Sheet Quantities.” IMF Economic Review 58 (1): 179-207.

Adrian, T., and H. Shin. 2014. "Procyclical Leverage and Value-at-Risk." Review of Financial Studies 27 (2): 373-403.

Adrian, T., N. Boyarchenko, and D. Giannone. 2018. "Vulnerable Growth," The American Economic Review, forthcoming.

Adrian, T., N. Boyarchenko, and D. Giannone. 2016. "Vulnerable Growth," Federal Reserve Bank of New York Staff Report 794.

Adrian, T., F. Grinberg, N. Liang, and S. Malik. 2018. "The Term Structure of Growth-atRisk," IMF Working Paper 18/180, International Monetary Fund, Washington, DC.

Adrian, T., D. He, F. Natalucci, and N. Liang. 2019a. "Macrofinancial Linkages and Global Financial Stability," forthcoming.

Adrian, T., J. Berrospide, S. Chavleishvili, R. Lafarguette, and S. Manganelli. 2019b. "Macro Stress Testing for Banks," forthcoming.

Amisano, G., and R. Giacomini. 2007. "Comparing Density Forecasts via Weighted Likelihood Ratio Tests," Journal of Business and Economic Statistics, 25(2): 177-190

Ang, A., M. Piazzesi, and M. Wei. 2006. "What Does the Yield Curve Tell Us about GDP Growth?" Journal of Econometrics 131 (1-2): 359-403.

Arregui, N., S. Elekdag, R. G. Gelos, R. Lafarguette, and D. Seneviratne. 2018. "Can Countries Manage Their Financial Conditions Amid Globalization?” IMF Working Paper 18/15, International Monetary Fund, Washington, DC.

Azzalini, A., and A. Capitanio. 2003. "Distributions Generated by Perturbations of Symmetry with Emphasis on a Multivariate Skew t-distribution." Journal of the Royal Statistical Society: Series B 65 (2): 367-89.

Bernanke, B. S., and A. S. Blinder. 1992. "The Federal Funds Rate and the Channels of Monetary Policy Transmission.” The American Economic Review 82 (4): 901-21.

Bianchi, J. 2011. "Overborrowing and Systemic Externalities in the Business Cycle." The American Economic Review 101 (7): 3400-26.

Brunnermeier, M. K., and L. H. Pedersen. 2009. "Market Liquidity and Funding Liquidity." Review of Financial Studies 22 (6): 2201-38. 
Brunnermeier, M. K., and Y. Sannikov. 2014. "A Macroeconomic Model with a Financial Sector." The American Economic Review 104 (2): 379-421.

Campbell, J. Y., M. Lettau, B. G. Malkiel, and Y. Xu. 2001. "Have Individual Stocks Become More Volatile? An Empirical Exploration of Idiosyncratic Risk." Journal of Finance 56 (1): 1-43.

Cardarelli, R., S. Elekdag, and S. Lall. 2011. "Financial Stress and Economic Contractions, Journal of Financial Stability" 7 (2): 78-97.

Claessens, S., M. A. Kose, and M. Terrones. 2012. "How Do Business and Financial Cycles Interact?" Journal of International Economics 87 (1): 178-90.

Corradi, V., and N. Swanson. 2006. "Predictive Density Evaluation.” In Handbook of Economic Forecasting, Volume 1, edited by G. Elliott, C. W. J. Granger, and A. Timmermann. Amsterdam: Elsevier.

Cornec, M. 2014. "Constructing a Conditional GDP Fan Chart with an Application to French Business Survey Data," OECD Journal: Journal of Business Cycle Measurement and Analysis 2013 (2) 109-27.

De Nicolò, G., and M. Lucchetta. 2017. “Forecasting Tail Risks.” Journal of Applied Econometrics 32 (1): 159-70.

Diebold, F.X., T.A. Gunther, A.S. Tay. 1998. "Evaluating Density Forecasts, with Applications to Financial Risk Management," International Economic Review, 39: 863883.

Elekdag, S. and P. Kannan. 2009. "Incorporating Market Information into the Construction of the Fan Chart," IMF Working Paper 09/178, International Monetary Fund, Washington, DC.

Estrella, A., and G. A. Hardouvelis. 1991. "The Term Structure as a Predictor of Real Economic Activity." Journal of Finance 46 (2): 555-76.

Estrella, A., and F. S. Mishkin. 1998. "Predicting U.S. Recessions: Financial Variables as Leading Indicators.” Review of Economics and Statistics 80 (1): 45-61.

Gertler, M., N. Kiyotaki, and A. Prestipino. 2017. "Wholesale Banking and Bank Runs in Macroeconomic Modeling of Financial Crises.” NBER Working Paper 21892, National Bureau of Economic Research, Cambridge, MA.

Gilchrist, S., and E. Zakrajšek. 2012. "Credit Spreads and Business Cycle Fluctuations.” The American Economic Review 102 (4): 1692-720. 
Hatzius, J., P. Hooper, F. S. Mishkin, K. L. Schoenholtz, and M. M. Watson. 2010.

"Financial Conditions Indexes: A Fresh Look after the Financial Crisis." NBER Working Paper 16150, National Bureau of Economic Research, Cambridge, MA.

He, Z., and A. Krishnamurthy. 2013. "Intermediary Asset Pricing." The American Economic Review 103 (2): 732-70.

IMF (International Monetary Fund). 2008. "Financial Stress and Economic Downturns." In World Economic Outlook (October), Chapter 4. Washington, DC: International Monetary Fund.

. 2014. "Staff Guidance Note on Macroprudential Policy_Detailed Guidance on Instruments.” IMF Policy Paper, International Monetary Fund, Washington, DC.

. 2017a. "Are Countries Losing Control of Domestic Financial Conditions?” In Global Financial Stability Report (April), Chapter 3. Washington, DC: International Monetary Fund.

. 2017b. "Financial Conditions and Growth at Risk." In Global Financial Stability Report (October), Chapter 3. Washington, DC: International Monetary Fund.

. 2017c. "Household Debt and Financial Stability." In Global Financial Stability Report (October), Chapter 2. Washington, DC: International Monetary Fund.

. 2018a. “A Bumpy Road Ahead.” In Global Financial Stability Report (April), Chapter 1. Washington, DC: International Monetary Fund.

. 2018b. "A Decade after the Global Financial Crisis: Are We Safer?" In Global Financial Stability Report (October), Chapter 1. Washington, DC: International Monetary Fund.

. 2018c. "Peru: Financial System Stability Assessment." Country Report No. 18/238, International Monetary Fund, Washington, DC.

. 2018d. "Portugal Article IV Consultation.” Country Report No. 18/273, International Monetary Fund, Washington, DC.

. 2018e. "Singapore Article IV Consultation." Country Report No. 18/245, International Monetary Fund, Washington, DC.

Kiyotaki, N., and J. H. Moore. 1997. "Credit Cycles.” Journal of Political Economy 105 (2): 211-48.

Koenker, R. 2005. Quantile Regression. Cambridge, U.K.: Cambridge University Press. 
Komunjer, I. 2013. "Quantile Prediction.” In Handbook of Economic Forecasting, Volume 2, Part B, edited by G. Elliott and A. Timmermann. Amsterdam: Elsevier.

Korinek, A., and A. Simsek. 2016. "Liquidity Trap and Excessive Leverage." The American Economic Review 106 (3): 699-738.

Lafarguette, R. 2019. “Growth at Risk Tool: Technical Appendix.” Mimeo., International Monetary Fund, Washington, DC. Available on https://github.com/IMFGAR/GaR

Laurent, R. D. 1988. "An Interest Rate-Based Indicator of Monetary Policy.” Federal Reserve Bank of Chicago Economic Perspectives 12 (1): 3-14.

Philippon, T. 2009. “The Bond Market's q.” Quarterly Journal of Economics 124 (3): 101156.

Stock, J. H., and M. W. Watson. 2003. "Forecasting Output and Inflation: The Role of Asset Prices." Journal of Economic Literature 41 (3): 788-829.

Tay, A. S., and K. F. Wallis. 2000. "Density Forecasting: A Survey.” Journal of Forecasting 19 (4): 235-54. 